\title{
Das Verhalten der antiproteolytischen Substanzen im Blutserum bei der Epilepsie.
}

\author{
Von \\ Dr. Stefan Rosental.
}

(Aus dem Institut für allgemeine und experimentelle Pathologie [Vorstand: Hofrat Paltauf] und der Klinik für Psychiatrie und Neurologie [Vorstand: Hofrat Wagner von Jauregg] in Wien.)

(Eingegangen am 3. Oktober 1910.)

Die in mancher Hinsicht widersprechenden Angaben über das Verhalten des Stoffwechsels bei der Epilepsie wurden durch die Forschungen der letzten Jahre teilweise aufgeklärt. Die Untersuchungen von Rohd $\mathrm{e}^{33}$ ) haben erwiesen, daß eine Vermehrung der Harnsäureausscheidung vor dem Anfall, welche $\mathrm{Haig}^{18}$ ) angegeben und im Sinne einer krampferregenden Retention gedeutet hat, nicht besteht und daß die wirklich stattfindende postparoxysmale Steigerung der Harnsäureproduktion auf das Zugrundegehen der während des Anfalls vermehrten Leukocyten zurückgeführt werden kann. Die letzte Annahme wurde neuerdings von Tintemann $n^{37}$ ) einer Kritik unterzogen; denn die Leukocytose soll bei alfen Epileptikern entsprechend der Intensität der Insulte auftreten, dagegen besteht die vermehrte Bildung der Harnsäure nur in manchen Fällen, kann aber auch nach den leichten Anfällen in ausgedehntem Maße zum Vorschein kommen. Das Wesen der Stoffwechselanomalie bei der Epilepsie liegt nach Rohde in einer Retention des Stickstoffes, welche sogar in der interparoxysmalen Zeit in geringem Maße besteht, aber vor dem Insult bedeutend ansteigt. Während die Retention vor der Anfallszeit ihr Maximum erreicht, kommt es auch zu einer Verzögerung des Eiweißabbaues. Diese qualitative intermediäre Anomalie findet ihren Ausdruck in einer gesteigerten Abgabe der ätherlöslichen organischen Säuren, welche schon vor dem Eintritt der Anfälle beginnt, nach der epileptischen Entladung, sogar wenn diese ohne Asphyxie oder starke Krämpfe verlaufen ist, noch ansteigt und ungefähr nach einer halben Stunde abgeschlossen ist. Während auf der Höhe der Ausscheidung dieser Substanzen sich die Fleischmilchäure, welche schon Inoye und Saiki ${ }^{22}$ ) nachgewiesen und als eine Folge der durch die Krampfasphyxie bedingten Oxydationsstörung gedeutet hatten, als der Hauptbestandteil des Ätherextraktes erwiesen 
hat, konnte die ätherlösliche Komponente des präparoxysmalen Urins nicht mit derselben identifiziert werden, was auch $\mathrm{Ka}$ uf $\operatorname{mann}^{23}$ ) betont hat. Deshalb vermutet Allers ${ }^{1}$ ), daß es sich vor dem Anfall hauptsächlich um die Bildung einer stickstoffhaltigen intermediären Verbindung handeln könnte. Durch die intermediäre Milchsäurebildung ist schon eine Bedingung für die Ammoniakvermehrung gegeben; dann wird die letztere durch die leukocytogene Entstehung der Harnsäure und der Phosphorsäure befördert. Es ist deshalb selbstverständlich, daß sich im Blute während einer Anfallsserie, wie es schon Krainsky ${ }^{24}$ ) nachgewiesen hat, eine vermehrte Ammoniakmenge befindet und im Urin ausgeschieden wird, wodurch auch die von vielen Autoren angegebene hypertoxische Wirkung der epileptischen Sera und der Urine aus der postparoxysmalen Zeit bedingt sein dürfte. Die Vermehrung des Ammoniaks ist aber zu gering, um als ein Ausdruck einer Acidosis angesehen zu werden, welche die epileptischen Anfälle, wie es $\mathrm{Kaufmann}{ }^{23}$ ) vermutet, verursachen könnte, um so mehr, als die Säurebildung ihren Höhepunkt erst nach dem Insult erreicht.

Der Befund abnormer Ausscheidungen insbesondere der ätherlöslichen organischen Säuren zeigt aber noch nicht, wann dieselben im Organismus gebildet werden; ob sie selbst die toxischen Substanzen oder die Abbauprodukte derselben sind. Wenn die ätherlöslichen Substanzen resp. die Milchsäure sogar erst nach dem Anfall ausgeschieden werden, so besteht trotzdem die Möglichkeit, daß dieselben oder wahrscheinlich ihre ebenfalls abnormen Vorstufen schon während der anwachsenden N-Retention sich im Blutserum angehäuft hatten und erst durch den Krampfanfall zur Ausscheidung gelangt sind. Ebenso ist es nicht vollständig aufgeklärt, wodurch die Verlangsamung des N-Stoffwechsels bei der Epilepsie bedingt ist.

Der intermediäre Eiweißabbau vollzieht sich in erster Linie unter der Wirkung proteolytischer Organfermente, welche ein ähnliches Spaltungsvermögen wie die entsprechenden Verdauungsfermente besitzen und sogar die Eiweißhydrolyse zu einem weiteren Stadium wie das enterogene Trypsin bringen. Während dieser Vorgang sich im enzymhaltigen Gewebe abspielt, wird er, wie der gesamte Stoffwechsel, durch die Tätigkeit der innersekretorischen Organe, welche an das Blut die entsprechend wirkenden Substanzen abgeben, reguliert*). Die Produkte der inneren Sekretion gelangen zur Wirkung in den enzymhaltigen Organen, welche sich ebenfalls in einem fortwährenden Stoffaustausch mit dem Blute befinden. Das Blutserum enthält wohl die proteolytischen Organfermente; die Wirkung der letzteren wird aber dort durch einen hemmenden Einfluß der ätherlöslichen

*) Näheres siehe Biedl, Innere Sekretion 1910. 
Substanzen, welche sich schon im normalen Serum befinden und bei manchen pathologischen Zuständen noch vermehrt sind,paralysiert. Die Untersuchungen von Claude und Schmiergeld ${ }^{11}$ ) haben ergeben, daß bei der Epilepsie die Drüsen mit innerer Sekretion gewöhnlich verändert sind; es wurden nämlich in den meisten Fällen sklerotische Vorgänge an der Thyreoidea, welche einer Hypofunktion dieses acceleratorischen Organes entsprechen sollen, festgestellt, während andere Drüsen seltener und verschiedenartig bezüglich des Funktionszustandes verändert werden und das Pankreas sich meistens als vollkommen normal erwiesen hat.

Die Tatsache, daß bei der Epilepsie einerseits vor der Anfallsserie abnorme Zustände der intermediären Proteolyse im Sinne einer Verzögerung und eine vermehrte Bildung der ätherlöslichen Substanzen nachgewiesen sind und daß anderseits Veränderungen in den Organen, welche den Eiweißabbau durch ihre Sekrete auf dem Blutwege regulieren, festgestellt wurden, haben den Anlaß gegeben, die Untersuchungen über die Beziehung des Blutserums der Epileptiker zu der fermentativen Proteolyse anzustellen.

Die Erforschung der proteolytischen Fermente des intermediären Stoffwechsels und besonders der direkte Nachweis derselben im Blutserum unterliegt großen Schwierigkeiten durch das erwähnte Vorhandensein der hemmend wirkenden Substanzen, welche bei Reagenzglasversuchen mit Blutserum die proteolytischen Fermente gewöhnlich nicht nur neutralisieren, sondern sogar überdecken. Man muß deshalb auf die derartig entstehende Blutferment-Antikörperverbindung verzichten und kann nur diejenige Menge der antiproteolytischen Hemmungssubstanzen, welche bei der Absättigung des Fermentes ungebunden bleiben und sich frei im Serum befinden, bestimmen, indem man bekannte Mengen eines anderweitigen, aber gleichartig wirkenden proteolytischen Fermentes zusetzt und die zur vollständigen Neutralisierung des freien Antifermentes nötige Quantität feststellt. Aus diesem Verhalten dürfen natürlich keine direkten Schlüsse auf den Gehalt der Körpersäfte an den bei dem Eiweißabbau wirkenden Fermenten und auf den Zustand des Intermediärstoffwechsels gezogen werden.

Die Lehre von den Antifermenten des Blutes wurde durch die Forschungen von Müller und Joch ma $\mathbf{n}^{27}$ ) in vielfacher Weise gefördert. Diese Autoren haben einerseits die Dellenbildung auf den Serumund Löfflerplatten unter der Wirkung des in den Leukocyten (resp. im Eiter) enthaltenen proteolytischen Fermentes festgestellt, anderseits die Hemmung dieses Phänomens durch das Blutserum und andere Körperflüssigkeiten bei verschiedenen Krankheitszuständen studiert. Es war ein großer Fortschritt, als Marcus nachgewiesen hat, daß die 
antiproteolytische Hemmungswirkung nicht nur auf das Leukocytenferment ausgeübt wird, sondern in gleicher Weise auch dem Trypsin gegenüber zum Vorschein kommt. Dementsprechend konnte das Müllersche Plattenverfahren módifiziert werden. Bald danach hat die Bestimmung der antitryptischen Kraft eine Neugestaltung durch die Anwendung des Fuld-Großschen Verfahrens, welches von G. v. Bergmann $n^{5}$ in die klinische Serologie eingeführt wurde und auch diesen Untersuchungen zugrunde liegt, erfahren. Die Ergebnisse dieser Methode sind nur dann für die vergleichenden Bestimmungen verwertbar, wenn die vielen möglichen Fehlerquellen bei der Anstellung der Versuche und bei der Verwertung der Resultate vermieden werden. Deshalb gelten die Ergebnisse nur, wenn die Untersuchungen genau in der Form angestellt werden, wie sie hier geschildert wird.

\section{Die Bestimmung der antitryptisehen Kraft.}

Der Bestimmung des antiproteolytischen Vermögens des Blutserums geht die Feststellung des Trypsintiters ( $T t$ ) voraus; es wird also die

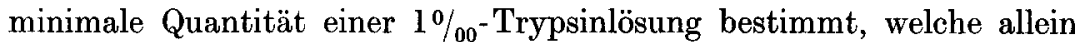
noch imstande ist, $2 \mathrm{~cm}$ einer $1 \%{ }^{-}$-Caseinlösung innerhalb 30 Minuten bei Temperatur von $37^{\circ}$ in einer derartigen Weise abzubauen, daß bei einem nachherigen Zusatz von 6 Tropfen einer 1 proz. alkoholischen Essigsäurelösung keine Niederschlagsbildung resp. Trübung eintreten kann, also daß das Casein, welches nur in alkalischen Medien löslich ist, vollständig verdaut ist. Während Bergmann und Meyer ${ }^{5}$ ), auch Ja kob ${ }^{20}$ ), dabei eine Reihe von Röhrchen, mit $0,1 \mathrm{ccm}$ einer 1\% $\%^{-}$ Trypsinlösung beginnend und um je $0,1 \mathrm{ccm}$ derselben ansteigend, geprüft haben und die „komplett verdauende“ Dose erst bei Anwendung von $0,5 \mathrm{ccm}$ ihrer Lösungen gefunden hatten, wobei $0,4 \mathrm{ccm}$ noch eine „Spur" Trübung geben sollte, habe ich eine folgende Reihe von zehn Röhrchen mit Trypsinlösung angewandt: $0,05-0,1-0,15-0,2-0,25-$ $0,3-0,4-0,5-0,6-\ldots 1,0$.

Es hat sich dabei herausgestellt, daß gewöhnlich schon 0,2 Trypsin die Caseinlösung vollständig gelöst hat, demnach als Trypsintiter anzusehen war. Dabei muß betont werden, daß die Trypsinlösungen genau nach den Vorschriften von Bergmann und Meyer ${ }^{5}$ ) bereitet wurden, nämlich $0,25 \mathrm{~g}$ Trypsini pur. (Grübler) wurde in $25 \mathrm{ccm}$ 0,85 proz. Kochsalzlösung gelöst und nach Zusatz von $0,25 \mathrm{com}$ einer Normalsodalösung auf $250 \mathrm{ccm}$ mit der Kochsalzlösung aufgefüllt. Was die Zubereitung des Caseins anbetrifft, so wurde 0,25 des Präparates mit $25 \mathrm{ccm}$ destillierten Wassers versetzt, nach Zusatz von 15 Tropfen einer Normalsodalösung unter leichtem Erwärmen gelöst und mit destilliertem Wasser auf $250 \mathrm{ccm}$ aufgefüllt.

Nachdem die Kraft der Trypsinlösung bekannt ist, folgt die Fest- 
stellung derjenigen Mengen derselben, welche nötig ist, um $2 \mathrm{ccm}$ der $1 \% 0^{-}$-Caseinlösung bei Gegenwart von $0,2 \mathrm{ccm}$ einer 5 proz. Lösung $(=0,01 \mathrm{ccm})$ des zu untersuchenden Blutserums unter denselben übrigen Bedingungen und in der gleichen Weise wie bei der Bestimmung des Trypsintiters zu verdauen. Man verwendet dazu eine Reihe der Trypsinlösungen, welche mit der allein ,,komplett verdauenden“ Dose beginnt und um je $0,1 \mathrm{ccm}$ ansteigt. Die größte Quantität der Trypsinlösung, welche noch nicht die Hemmungswirkung des Serums zu überwinden vermag, und bei welcher nach Zusatz von Essigsäure noch eine Spur Trübung hervorgetreten ist, kann man He m m ungs titer (Ht), wie es $\mathrm{Becker}^{4}$ ) vorgeschlagen hat, benennen. Bergmann mit seinen Mitarbeitern und Becker selbst haben einfach mit der gefundenen Höhe des Hemmungstiters die antitryptische Kraft der geprüften Sera bezeichnet. Es ist aber viel rationeller, bei der Beurteilung der Frgebnisse einer Versuchsreihe diejenige Menge der Trypsinlösung in Betracht zu ziehen, welche trotz der hemmenden Wirkung des Serums eine vollkommene Verdau ung durchzuführen imstande ist, also bei unserer Versuchsanordnung um $0,1 \mathrm{ccm}$ größer ist, als der Hemmungstiter, und als Neutralisationstiter (Nt) bezeichnet werden kann. Denn diejenige Trypsinmenge, welche durch die Einwirkung der angewandten $0,01 \mathrm{ccm}$ des Serums paralysiert ist, wird durch die Differenz zwischen dem Neutralisationstiter und dem Trypsintiter ausgedrückt. Eine Berechnung der antitryptischen Kraft durch die Bestimmung des Differenzindexes (DI) gibt aber ebenfalls keine absoluten Werte. Denn die Trypsinlösungen zeigen, obwohl man sie in gleicher Verdünnung, $1 \%$, vorbereitet, eine differente Verdauungskraft, was die Ergebnisse der Antitrypsinbestimmungen bei verschiedenen Trypsintitern nicht gestattet. Deshalb hat $J \mathrm{a} \mathrm{kob}^{22}$ ) versucht, diesen Übelstand durch die Einführung einer Indexberechnung, welche trotz der wechselnden Höhe des Trypsintiters immer absolute vergleichbare Resultate geben sollte, zu überwinden; er berechnet die antitryptische Kraft durch die Zahl, welche angibt, um wieviel Prozent man die ,allein verdauende Trypsinmenge" $(\mathrm{Tt})$ vermehren muß, um die Hemmungswirkung von $\mathbf{l} \mathrm{ccm}$ des betreffenden Serums zu überwinden. Dieser absolute Index $(\mathrm{AI})=\frac{\left(\mathrm{a}_{1}-\mathrm{a}\right) 100}{\mathrm{a}}$, wobei a dem Tt gleicht und durch $a_{1}$ nach Jakob diejenige Trypsinmenge bezeichnet werden soll, bei welcher in Gegenwart des Serums ,noch eine leichte Trübung auf-

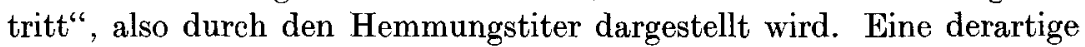
Deutung widerspricht der angeführten Formulierung der Indexberechnung; es ist zweckmäßiger, in derselben Weise wie bei der Berechnung des DI vorzugehen und unter $a^{1}$ diejenige Trypsinmenge zu verstehen, bei welcher eine vollkommene Verdauung eingetreten ist, d.h. den 
Neutralisationstiter. Demnach wird die modifizierte Form des absoluten Indexes sich folgenderweise gestalten: $\mathrm{AI}=\frac{100(\mathrm{Nt}-\mathrm{Tt})}{\mathrm{Tt}}=\frac{\mathrm{DI} \cdot 100}{\mathrm{Tt}}$. Die Brauchbarkeit der Jakobschen Methode für eine vergleichbare Indexberechnung wurde mir aber sehr bedenklich, nachdem ich einige Sera zugleich mit verschieden starken Trypsinlösungen geprüft hatte; denn die dabei gewonnenen Resultate haben keine gewünschte Ubereinstimmung gezeigt. Wenn z. B. bei $\mathrm{Tt}=0,15$ ein Serum den $\mathrm{Nt}=0,9$ zeigt, so ist dabei $\mathrm{DI}=0,75$ und $\operatorname{der} \mathrm{AI}=\frac{0.75 \cdot 100}{0,15}=500$; bei der gleichzeitigen Prüfung desselben Serums mit $\mathrm{Tt}=0,2$ wäre nach der Formel $\left(\frac{\mathrm{Nt}-0,2}{0,2}=5\right)$ zu erwarten, daß die Neutralisation im Röhrchen, welches 1,2 ccm der Trypsinlösung enthält, eintreten wird. Es kann aber vorkommen, daß die vollkommene Lösung des Caseins schon bei der Einwirkung von 1,1 der Trypsinlösung, ja sogar bei 1,0 erfolgt. Durch ein derartiges Verhalten können große Fehler in der Berechnung entstehen; deshalb bin ich zur Überzeugung gekommen, daß man unbedingt mit den Trypsinlösungen gleichen Titers arbeiten muß, was übrigens leicht zu erreichen ist. Wenn man die $1 \%$-Lösungen einige Stunden vor dem Gebrauch vorbereitet und dann im Eiskasten aufbewahrt, damit das unter Erwärmung gelöste Casein abgekühlt wird, so kommt eine Abweichung von unserem gewöhnlichen Titer 0,2 nur selten vor. Falls aber der Vorversuch, der ständig auszuführen ist, ergibt, daß die $1 \%$-Trypsinlösung eine stärkere Verdauungskraft besitzt, z. B. den Titer 0,15 zeigt, so kann man gewöhnlich durch Zusatz von 25-33 ccm der phys. Kochsalzlösung den nötigen Titer 0,2 erreichen. Wenn umgekehrt z. B. erst 0,25 der Trypsinlösung sich als Tt ergeben hatte, so habe ich der geringen Kraft derselben durch eine vorsichtige Verdünnung der Caseinlösung mit destilliertem Wasser entgegenzuwirken versucht, damit $0,2 \mathrm{ccm}$ der Trypsinlösung eine geringe Arbeitsleistung auszuführen hätte und eine vollkommene Verdauung der $2 \mathrm{ecm}$ eines schwächer konzentrierten Caseins durchführen könnte. Bei einer ausschließlichen Anwendung der Trypsinlösungen mit 'Tt 0,2 und bei einer Berechnung der damit gewonnenen Resultate nach der angeführten Formel bekommt man für die entsprechenden Indexe derartige Zahlen, daß je zwei nacheinander folgende Stufen der antitryptischen Kraft voneinander um 50 differieren. Man kann deshalb, unter der Bedingung der Ständigkeit des Tt, derartige ,absolute“ Indexe der Übersichtlichkeit wegen mit 50 dividieren, und man erreicht in dieser Weise Zahlen, welche dem DI für $0,1 \mathrm{ccm}$ entsprechen und für die Benennung des Befundes zweckmäßig sind, wie aus der beigefügten Tabelle I ersichtlich wird. 
Tabelle I. Indextafel bei $\mathrm{Tt}=0,2$.

\begin{tabular}{|c|c|c|c|c|}
\hline Ind. & $\mathrm{st}$ & $\begin{array}{c}\text { DJ } \\
\text { p. } 0,01 \\
\end{array}$ & $\begin{array}{c}\text { AJ } \\
\text { p. } 1,0\end{array}$ & $\begin{aligned} & 1 / 50 \mathrm{AJ} \\
= & \mathrm{DJ} \mathbf{~ p . 0} 0,1\end{aligned}$ \\
\hline 0 & 0,2 & 0 & 0 & 0 \\
\hline I & 0,3 & 0,1 & 50 & 1 \\
\hline II & 0,4 & 0,2 & 100 & 2 \\
\hline III & 0,5 & 0,3 & 150 & 3 \\
\hline IV & 0,6 & 0,4 & 200 & 4 \\
\hline $\mathrm{V}$ & 0,7 & 0,5 & 250 & 5 \\
\hline$V I$ & 0,8 & 0,6 & 300 & 6 \\
\hline VII & 0,9 & 0,7 & 350 & 7 \\
\hline VIII & 1,0 & 0,8 & 400 & 8 \\
\hline IX & 1,1 & 0,9 & 450 & 9 \\
\hline $\mathrm{X}$ & 1,2 & 1,0 & 500 & 10 \\
\hline XI & 1,3 & 1,1 & 550 & 11 \\
\hline XII & 1,4 & 1,2 & 600 & 12 \\
\hline
\end{tabular}

Was die Hemmungswirkung der normalen menschlichen Sera anbetrifft, so haben Bergmann und Meyer ${ }^{5}$ ) angegeben, daß dieselbe durchschnittlich bis $0,5-0,6$ einer Trypsinlösung mit $\mathrm{Tt} 0,5$ reicht, daß also diese Zahlen als normaler Hemmungstiter und $0,6-0,7$ als der entsprechende Neutralisationstiter anzusehen sind; demnach sollen die normalen Sera einen DI von $0,1-0,2$ zeigen. Wenn das antitryptische Vermögen noch gegenüber $0,8-0,9 \mathrm{ccm}$ der Trypsinlösung in Form einer leichten Trübung auftritt und die Verdauung des Caseins erst bei $0,9-1,0$ zustande kommt, soll der daraus folgende DI 0,4 resp. 0,5 schon eine ,deutliche" Steigerung der antitryptischen Kraft bedeuten. Die Vergleichstabelle II zeigt, daß $\mathrm{Ja} \mathrm{k} \mathrm{ob}^{20}$ ) mit seiner Berechnungsmethode zu ganz ähnlichen Resultaten gekommen ist; auf dieselben hat sich auch $\mathrm{Jach}^{19}$ ) bei der Beurteilung seiner Befunde gestützt.

Tabelle II. Vergleichstafel bei $\mathrm{Tt}=0,5$

\begin{tabular}{|c|c|c|c|c|}
\hline n. Bergmann $=\mathbf{H t}$ & n. Becker $=\mathrm{Nt}$ & $\begin{aligned} & \text { n. Fürst } \\
= & \text { DJ p. } 0,01\end{aligned}$ & $\begin{aligned} & \text { n. Jacob } \\
= & \mathbf{A} \mathbf{J} \text { p. } 1,0\end{aligned}$ & Bedeutung \\
\hline bis 0,5 & 0,5 & 0 & & -- \\
\hline $0,5-0,6$ & $0,6-0,7$ & $0,1-0,2$ & $20-40$ & - \\
\hline 0,7 & 0,8 & 0,3 & $40-60$ & \pm \\
\hline $0,8-0,9$ & $0,9-1,0$ & $0,4-0,5$ & $65-95$ & + \\
\hline $1,0-1,5$ & $1,1-1,5$ & $0,6-1,0$ & $100-200$ & ++ \\
\hline aber 1,5 & utber 1,5 & über 1,0 & über 200 & $+t+$ \\
\hline
\end{tabular}

Da ich mit einer bedeutend stärker wirkenden Trypsinlösung, wie die angeführten Autoren, gearbeitet hatte, so war es zu erwarten, daß die Nt der Sera entsprechend niedriger ausfallen, und zwar nicht nur 
um die Differenz der Tt, welche in diesem Falle $(0,5-0,2)=0,3$ war, sondern noch viel kleinere Zahlen ergeben werden; denn diese Werte und dementsprechend auch die Hemmungsdifferenzen (DI) müssen nach der Formel proportionell ihren $\mathrm{Tt}$ sein, um beim Dividieren mit den letzteren einen gleichen absoluten Indexwert zu geben. Wenn z. B. ein Serum $A I=200$ hat, so wird

$$
\begin{array}{r}
\text { bei } \mathrm{Tt}=0,2 \text { der } \mathrm{Nt}=0,6 \text { resp. der } \mathrm{DI}=0,4 \\
" \quad "=0,3 \quad, \quad=0,9 \quad " \quad " \quad "=0,6 \\
" \quad "=0,5 \quad "=1,5 \quad " \quad " \quad "=1,0 \\
\text { demnach ist } \mathrm{Nt}_{0,2}=\frac{\mathrm{Nt}_{0,5} \cdot 0,2}{0,5} \text { resp. } \mathrm{DI}_{0,2}=\frac{\mathrm{DI}_{0,5} \cdot 0,2}{0,5}
\end{array}
$$

Es war für mich eine große Überraschung, als ich festgestellt hatte, daß die normalen Neutralisationskoeffizienten für die menschlichen Sera trotz des starken Titers meiner Trypsinlösung nicht niedriger waren, wie die von Bergmann und $\mathrm{Jakob}$ bei Tt 0,5 erhobenen Befunde, sondern im Gegenteil noch bedeutend höhere Werte zeigten. Nach meinen Ergebnissen haben die Sera vollkommen gesunder Leute einen Nt von $0,6-0,8$, manchmal sogar 0,9 , sind also durch Ind. IV-VI (resp. VII) zu bezeichnen. Während der Verdauung, nach starken Muskelanstrengungen und bei Frauen in der prämenstruellen Zeit findet sich als Maximalgrad der normalen antitryptischen Kraft der Ind. VII, welcher zwar auf eine geringe Steigerung des Hemmungsvermögens

\begin{tabular}{|c|c|c|c|c|}
\hline Ind. & $\begin{array}{c}\mathrm{Nt} \\
\text { bei 'Tt } 0,2\end{array}$ & ('har. & Steigung & $\begin{array}{c}\text { Gehalt } \\
\text { an ATr. Sub }\end{array}$ \\
\hline IV & 0,6 & & \multirow{3}{*}{ keine } & \multirow{4}{*}{$\begin{array}{l}\text { niedrig } \\
=\mathrm{NW}\end{array}$} \\
\hline $\mathrm{V}$ & 0,7 & - & & \\
\hline VI & 0,8 & & & \\
\hline VII & 0,9 & t. & gering & \\
\hline VIII & 1,0 & $t$ & dentlich & \multirow{6}{*}{$\begin{array}{l}\text { hoch } \\
=\mathrm{HW}\end{array}$} \\
\hline IX & 1,1 & & & \\
\hline$\dot{x}$ & 1,2 & & atorre & \\
\hline XI & 1,3 & $+T$ & Stark & \\
\hline XII & 1,4 & & & \\
\hline XIII & 1,5 & + & & \\
\hline
\end{tabular}
hinweist, aber unter obigen Bedingungen nichts Pathologisches bedeutet (siehe Tabelle III).

Tabelle III. Benennung der Indexwerte.

Derartige Befunde, welche im Vergleich mit den Ergebnissen aller bisherigen Autoren paradox sind, haben mich zur Prüfung der Methodik veranlaßt; es wurde in erster Linie die Frage aufgestellt, ob der Tt. 0,2 richtig bestimmt wurde, oder derselbe nicht 
vielleicht schwächer war, wodurch die hohen Neutralisationstiter als dem Tt proportionell zu erklären wären. Ich konnte mich aber überzeugen, daß das vollständig verdaute Casein unabhängig davon, ob man den Verdauungsversuch mit oder ohne Serum angestellt hatte, also ebenso bei der Bestimmung des $\mathrm{Tt}$ wie auch von $\mathrm{Nt}$ noch vor dem Zusatz von Essigsäure nie ,vollkommen" klar ist, wie es Bergmann und Me yer über die Wirkung der ,,komplett lösenden“ Trypsindose angeben, sondern immer eine leichte Opalescenz, welche auch nach Zusatz von Essigsäure bestehen bleibt, zeigt. Dieses Verhalten kommt am deutlichsten in den Eprouvetten mit $5 \mathrm{ccm}$ Inhalt und von $9 \mathrm{~mm}$ Durchmesser zum Vorschein, wenn die Essigsäure in alkoholischer Lösung zugetropft wird. Dadurch wird nicht nur die Gefahr, daß, wie es Fuld hervorgehoben hat, ein Überschuß an wässeriger Essigsäure den Niederschlag lösen könnte, vollkommen ausgeschlossen, sondern es ist auch die Möglichkeit gegeben, die Unterschiede der Resultate in verschiedenen Röhrchen genauer zu beurteilen. Während beim Zusatz einer wässerigen Essigsäurelösung dieselbe sich rasch mit dem Casein mischt und eine diffuse Trübung hervorruft, bleibt die leichtere alkoholische Lösung oberhalb des opalescierenden Caseins; deshalb bedingt sie hier nur an der Grenze beider Lösungen die Bildung eines weißen trüben Ringes, welcher verschiedene Grade bezüglich der Höhe und der Dichtigkeit in Abhängigkeit von der Quantität des unverdaut gebliebenen Caseins besitzt, dabei aber viel intensiver ist, wie die entsprechenden diffusen Trübungen, welche von den Opalescenzen des vollkommen verdauten Caseins nur schwer zu unterscheiden sind. Was die letzte Fehlerquelle, z. B. bei der Bestimmung des Tt anbetrifft, so kommt es vor, daß, während nach Anwendung von $0,05 \mathrm{~cm}$ der Trypsinlösung eine deutliche Trübung, bei 0,1 eine schwache und bei 0,15 eine Spur Trübung entsteht, auch das Röhrchen mit $0,2 \mathrm{ccm}$ noch eine Opalescenz zeigt, was man als Beweis einer unvollkommenen Verdauung betrachten könnte und deshalb den $\mathrm{Tt}$ höher verlegen möchte. Es ist in derartigen Fällen das Verhalten der nächsten Röhrchen mit einem höheren Trypsingehalt, bei weichen entsprechend der geschilderten stufenweisen Abschwächung der Trübung bei, vorausgegangenen, um 0,5 differierenden Werten eine vollkommene Klärung zu erwarten wäre, entscheidend. Wenn in denselben ebenfalls eine trübe Opalescenz, wie bei 0,2 der Trypsinlösung, mit derselben Intensität vorhanden ist, so schließt diese Tatsache die Ungenauigkeit der TtBestimmung aus; deshalb habe ich immer neben der aufsteigenden Reihe $0,05-\ldots-0,6$ auch eine Kontrollösung mit 1,0 Trypsin, welche trotz des hohen Trypsingehaltes doch eine Opalescenz nach Zusatz von Essigsäure zeigte, aufgestellt. Es empfiehlt sich außerdem dabei, die Röhrchen vor dem Zusatz von Casein mit phys. Kochsalzlösung un- 
gefähr auf 0,5 ccm aufzufüllen, damit das Gesamtvolumen demjenigen entspricht, mit welchem man später bei der Feststellung des Neutralisationstiters zu tun haben wird. Dadurch wird die Eventualität ausgeschlossen, daß das Trypsin bei einem geringen Gesamtvolumen resp. durch eine stärkere Konzentration eine größere Verdauungskraft entfalten könnte, wie es bei derselben Quantität dieses Ferments geschieht, wenn die Gesamtmenge nur durch Zusatz der Kochsalzlösung größer ist.

Bei der Bestimmung des Neutralisationstiters der Sera darf man ebenfalls nicht nach dem absoluten Grade der Opalescenz, sondern nach dem Ausbleiben einer weiteren Abnahme der Intensität der letzten in der Reihe urteilen; ständig muß dabei eine mit Kochsalzlösung entsprechend aufgefüllte Kontrolle, welche die Tt-Dose ohne Serumzusatz enthält, beigelegt werden, damit die Opalescenzen verglichen werden könnten. Was das Auffüllen der aufsteigenden Reihe auf das gleiche Volumen mit Kochsalzlösung anbetrifft, so kann das schon vor dem Zusatz von Casein ausgeführt werden. Die Trypsinlösung soll aber in allen Röhrchen, trotz der wechselnden Menge des Fermentes, bei derselben Konzentration von den Hemmungskörpern des Serums beeinflußt werden; deshalb ist es nötig, sogar schon vor dem Zusatz der Kochsalzlösung das Serum-Trypsingemisch durchzuschütteln, was noch das zweitemal vor dem Auffüllen mit Casein und das drittemal nachher zu wiederholen ist.

\section{Das Wesen der antiproteolytischen Substanzen.}

Der Entwicklungsgang unserer Kenntnisse von der antiproteolytischen Wirkung hatte die Annahme zur Folge, daß diese Eigenschaft des Blutserums von der Leukocytose abhängig ist. Namentlich soll das beim Zerfall der polynucleären Leukocyten freiwerdende proteolytische Ferment (die Leukoprotease) einerseits zwar durch die Absättigung eines Teils des Antifermentes ein vorübergehendes Herabsinken des Hemmungsvermögens hervorrufen, anderseits aber danach eine gesteigerte Bildung des Antifermentes als eine endogene Immunitätsreaktion zustande bringen, woraus eine Erhöhung der antiproteolytischen Kraft resultieren soll. Die Identität des antileukoproteatischen Fermentes mit den antitryptischen Substanzen wurde von Jochmann und Kantorowic ${ }^{21}$ ) nachgewiesen; demnach hat man versucht, das Auftreten der von Brieger und Trebing ${ }^{8}$ ) als „Kachexiesymptom“ gedeuteten Steigerung der antitryptischen Kraft bei Carcinomen auf die Folgen der bei den malignen Geschwülsten bestehenden Leukocytose zurückzuführen. Nachdem aber das erhöhte antiproteolytische Vermögen des Blutserums auch bei manchen mit einer Leukopenie einhergehenden Erkrankungen festgestellt wurde, so 
hat man als Ursache der gesteigerten antitryptischen Kraft nicht nur den Leukocytenzerfall, sondern auch die Gewebseinschmelzung überhaupt angenommen und erklärte das Hemmungsvermögen ursprünglich ebenfalls als eine Wirkung der ,echten“ Antifermente, welche als eine Reaktion des Organismus auf die Überschwemmung der Körpersäfte mit den bei Gewebszerfall freiwerdenden Organfermenten entstehen sollen.

Es war ein Wendepunkt in der Lehre von den antiproteolytischen Hemmungskörpern, als Pick und Przibram ${ }^{33}$ ) die Ätherlöslichkeit derselben festgestellt hatten und dadurch die Grundlage der Auffassung, daß es sich beim Antitrypsin um direkte Zerfallsprodukte des Protoplasmas, namentlich um die Zellipoide handelt, geschaffen haben. Viele Untersuchungen, besonders die von Schwarz ${ }^{35}$ ) haben diese Annahme bestätigt und die Konstitution der Hemmungsstoffe näher aufgeklärt. Da es sich nämlich herausgestellt hat, daß der Ätherextrakt der Sera eine geringere antitryptische Hemmungskraft wie die letzteren besitzt, so müßte man annehmen, daß die Lipoide erst in Verbindung mit Eiweißkörpern als Lipoideiweißsubstanzen die volle antiproteolytische Wirkung entfalten können. Dann wurde das Verschwinden der Hemmungskraft nach den Ausfällen der Albumins des Serums durch die gesättigte Ammoniumsulfatlösung festgestellt; demnach wäre das Antitrypsin als eine Lipoid-Albuminverbindung aufzufassen; endlich wurde von Döblin ${ }^{12}$ ) und $\mathrm{Bauer}{ }^{3}$ ) die Thermostabilität der antitryptischen Hemmungskörper nachgewiesen, was ebenfalls gegen die Fermentnatur dieser Substanzen spricht.

Es soll aber nach Eisner ${ }^{14}$ ) für die Spezifizität des Antitrypsins die Tatsache sprechen, daß andere fermentative Prozesse, wie z. B. die Lipolyse, durch diese Hemmungskörper des Serums nicht beeinflußt werden; dieses Verhalten wurde festgestellt, indem die KobragiftLecithinhämolyse als lipolytisches System angewandt wurde. Derartige Befunde sind aber für die Annahme einer Spezifizität des Antitrypsins nicht zu verwerten, im Gegenteil, sie lassen sich sogar mit dem lipoiden Charakter der Hemmungskörper in Zusammenhang bringen. Wenn nämlich bei einem gesteigerten Protoplasmazerfall, besonders mit chronischem Verlauf, die Zellipoide durch eine längere Zeit in gesteigertem Maße an das Blutplasma abgegeben werden, so bewirken sie neben der direkt erzeugten Steigerung des antiproteolytischen Vermögens, auch eine „sekundäre" Erhöhung der lipolytischen Kraft, worauf neuerdings Wasserman ${ }^{38}$ ) hingewiesen hat. Ein derartiges Serum kann infolgedessen nicht die zur Erzeugung der Hämolyse notwendige Lecithinspaltung durch die Kobralipase hemmen; im Gegenteil, es könnte eventuell den Spaltungsprozeß durch seine eigene lipolytische Kraft nur steigern. 
Man muß betonen, daß auch die klinischen Tatsachen gegen die Fermentnatur des Antitrypsins sprechen; man findet z. B. bei Morbus Basedowii eine enorme Steigerung der antiproteolytischen Kraft, welche von K. Me yer ${ }^{26}$ ) sogar als ein pathognomonisches Zeichen dieser Erkrankung betrachtet wird. Wenn diese Erscheinung durch ein echtes Antiferment bedingt wäre, so müßten auch die proteolytischen Organfermente des Intermediärstoffwechsels durch den ,immunisatorisch" entstandenen Antikörper neutralisiert werden und man sollte demnach eine Verminderung des Eiweißstoffwechsels erwarten. Bekanntlich aber besteht bei der Basedowschen Krankheit eben das Gegenteil, nämlich der gesteigerte Eiweißabbau, was annehmen läßt, daß in derartigen Fällen die Steigerung der antitryptischen Kraft auf die Überschwemmung der Körpersäfte durch die beim gesteigerten Eiweißzerfall freiwerdenden Lipoideiweißverbindungen, zurückzuführen ist. Diese ätherlöslichen Abbaustoffe kreisen im Blutserum, bevor sie weiter verbrannt resp. ausgeschieden werden, sie können aber nicht von den Organenzymen gebunden werden, um dieselben in ihrer Wirkung zu neutralisieren, was die echten immunisatorisch erzeugten Antifermente tun müßten.

Allerdings kann die Möglichkeit des Vorkommens eines endogen entstandenen echten Antitrypsins nicht ausgeschlossen werden. Man muß die Tatsache berücksichtigen, daß das „Antitrypsin“, wie es schon Bauer ${ }^{3}$ ) betont hat, keine einheitliche Substanz ist, wofür die Differenzen in den chemischen und biologischen Eigenschaften der verschiedenen auf die Proteolyse hemmend wirkenden Körper sprechen. So können vielleicht bei manchen Krankheitszuständen sich abnorme Vorgänge in der inneren Sekretion resp. bei der Selbstregulation der Organfermente abspielen, wobei entweder ein im Pankreas gebildetes ,echtes“ Antitrypsin oder die lipoiden Sekretionsprodukte der Nebenniere im gesteigerten Maße an das Blut abgegeben werden und im Gegensatz zu den lipoidartigen Produkten der Gewebseinschmelzung die intermediäre Proteolyse hemmend beeinflußen; dabei müßte aber, im Gegensatz zum Verhalten des Eiweißabbaues bei Morbus Basedowii, eine Verlangsamung des Eiweißstoffwechsels bestehen und die dadurch entstandenen unvollständig abgebauten $\mathrm{Zwi}$ schenprodukte bei der Stoffabgabe auftreten. Wenn aber auch bei derartigen Zuständen, in welchen durch die Untersuchung des Endstoffwechsels eine Stickstoffretention und eine intermediäre Abbaustörung festgestellt wurde, zugleich ein erhöhtes antiproteolytisches Hemmungsvermögen des Serums nachgewiesen wird, so darf man doch nicht behaupten, daß diese Erscheinung durch einen gesteigerten Gehalt der Körpersäfte an Antitrypsin, welches die intermediäre Proteolyse herabsetzt, hervorgerufen wird. Es ist möglich, daß die Ver- 
langsamung des Eiweißabbaues beim unveränderten konstanten Gehalt des Organismus an antiproteolytischen Hemmungskörpern durch eine primäre Verminderung der proteoly tischen Organfermente bedingt wäre, was den gleichen Ausdruck bei der Bestimmung der antitryptischen Kraft des Blutserums bekommen hätte.

Es entsteht die Frage, in welcher Beziehung die bei manchen physiologischen Vorgängen und vielen pathologischen Zuständen bestehende Hyperleukocytose zur Steigerung der antitryptischen Kraft des Serums steht. Ist sie wirklich die Ursache der Vermehrung der Hemmungssubstanzen, welche in diesem Falle durch das Freiwerden des proteolytischen Leukocytenfermentes immunisatorisch erzeugt werden müßten, oder ist sie umgekehrt eine Reaktionserscheinung, welche durch die lipoiden Hemmungssubstanzen auf chemotaktischem Wege hervorgerufen wird und dieselben entfernen soll. Was die physiologischen Vorgänge anbetrifft, so besteht bekanntlich bei der Verdauung eine Vermehrung der Leukocyten, welche mit Hilfe der Phagocytose die Beförderung der resorbierten Nahrungsstoffe, eine Entgiftung derselben bewirken soll. Dementsprechend hat Gläßner ${ }^{16}$ ) eine Erhöhung der antitryptischen Kraft des Serums auf der Höhe der Verdauung nachgewiesen, was meine Untersuchungen am Menschen bestätigt haben. Es besteht gewöhnlich eine Differenz um 1-2 Grade des Indexes dem Serum des nüchternen Menschen gegenüber. Öfters wurde dabei beim normalen Menschen der Index VII festgestellt. Bemerkenswert ist, $\mathrm{da} B$ diese Steigerung besonders ausgeprägt bei den chylös getrübten Seris zum Vorschein kam; dieser Befund spricht für die Annahme, daß vielleicht die lipoiden Nährstoffe die Trypsinverdauung des Caseins hemmend beeinflussen können. Einen weiteren Beitrag liefert zu dieser Frage die Beobachtung, daß eine vorübergehende Erhöhung der antitryptischen Kraft bei einer gesteigerten Muskeltätigkeit aufzutreten pflegt, was an einigen Fällen der Jacksonschen Epilepsie sofort nach dem Insult beobachtet wurde, wobei die Indexe VII-X sich gezeigt haben. Bei der Muskelanstrengung besteht aber nach den Untersuchungen von Grawitz ${ }^{17}$ ) ebenfalls eine "myogene" Leukocytose, welche zur phagocytären Beseitigung der während der Muskelarbeit entstandenen Stoffwechselprodukte dienen soll, weshalb sie auch in Parallele zu der ,Verdauungsleukocytose“ zu setzen ist. Die Wirkung der myogenen Leukocytose soll sich ähnlich, wie die Steigerung der antitryptischen Kraft, sehr rasch, ungefähr innerhalb einer halben Stunde, abspielen, wonach das Blutbild das normale Verhalten bezüglich der Zahl und der Proportion der Leukocyten wiedererlangt. Während der Geburt entsteht durch die Kontraktion der Uterusmuskulatur, wie es Grawitz ${ }^{17}$ ) betont, eine Leukocytose, welche nach der Entbindung verschwindet; damit im Einklang stehen die Befunde von 
Becker ${ }^{4}$ ) über die Erhöhung des antiproteolytischen Vermögens des Serums während der Wehen und eine rasche postpuerperale Senkung derselben, welche der Abnahme der Leukocyten parallel zu gehen scheint. Diese Betrachtungen nähern uns der Annahme, daß die Leukocytose bei diesen physiologischen Vorgängen nicht als die Ursache der Steigerung der antitryptischen Kraft, sondern die beiden Erscheinungen als koordinierte betrachtet werden können. Die durch chemotaktische Wirkung der bei der Verdauung und der Muskelanstrengung in das Blut gelangenden Substanzen hervorgerufene Leukocytose dient zur Entgiftung und Wegschaffung der Assimilationsprodukte, wobei die proteolytischen Leukocytenfermente von den lipoiden Hemmungskörpern des Serums abgesättigt werden, was eine nachfolgende Senkung der antitryptischen Kraft verursacht.

\section{Das antiproteolytische Hemmungsvermögen bei den Abbauprozessen des Nervensystems.}

Das geschilderte Verhalten ist als die Ursache der Erhöhung des Hemmungsvermögens des Serums bei allen mit gesteigerter Gewebseinschmelzung einhergehenden resp. zur Kachexie führenden Krankheitsprozessen, also beim Carcinom, bei der Tuberkulose und, was für den Gegenstand dieser Untersuchung besonders wichtig ist, bei den durch einen fortschreitenden Abbau der Gehirnsubstanz sich auszeichnenden organischen Psychosen zu betrachten. Vor allem ist in dieser Hinsicht die progressive Paralyse bemerkenswert. Nach den Untersuchungen von Peritz ${ }^{28}$ ) soll der paralytische Prozeß durch eine Bindung des Lecithins der Gehirnsubstanz und des Knochenmarkes durch das Luestoxin entstehen, woraus eine Verarmung der entsprechenden Organe an Lecithin und wie es auch Bornstein ${ }^{7}$ ) bestätigt hat, eine Uberschwemmung des Blutserums mit diesem Lipoid resultieren. Deshalb besitzen auch die Blutsera der Paralytiker eine gesteigerte antitryptische Kraft, worauf zuerst $\mathrm{Jach}^{19}$ ) hingewiesen hat. .Da aber dieses auf die Lipoidnatur des Antitrypsins hindeutende Verhalten gleichzeitig von K. Me yer ${ }^{26}$ ) bestritten wurde, so habe ich 25 Sera von Paralytikern einer Prüfung unterzogen.

Obwohl hauptsächlich beginnende Paralysen, bei welchen der Ernährungszustand nicht bedeutend herabgesetzt war, benutzt wurden, befand sich, wie Tabelle IV zeigt, zwischen den 25 untersuchten Fällen kein einziger mit normalem Verhalten des Hemmungsvermögens des Blutserums; nur bei 4 Kranken war eine leichte Erhöhung nachzuweisen, die meisten Paralytiker $(15=60 \%)$ zeigten dagegen eine deutliche Steigerung, in 6 Fällen (24\%) wurde eine starke Steigerung der antitryptischen Kraft festgestellt. Man muß 
Tabelle IV. Paralysis progressiva.

\begin{tabular}{|c|c|c|c|c|c|}
\hline \multicolumn{3}{|c|}{ Antitr. Kraft } & \multirow{2}{*}{ Zahl } & \multirow{2}{*}{ Summa } & \multirow{2}{*}{$\%$} \\
\hline w. & Char. & Ind. & & & \\
\hline \multirow{3}{*}{$\mathrm{N}$} & - & V & 0 & 0 & 0 \\
\hline & & VI & 0 & & \\
\hline & + & VII & 4 & 4 & 16 \\
\hline \multirow{4}{*}{$\mathrm{H}$} & & VIII & 7 & & \\
\hline & + & IX & 8 & 15 & 60 \\
\hline & ++ & $\mathrm{X}$ & 5 & 6 & 24 \\
\hline & & $X 1$ & 1 & & \\
\hline
\end{tabular}

dabei erwähnen, daß die meisten Paralytikersera auch ein verändertes lipolytisches Vermögen (hauptsächlich im Sinne einer Steigerung) besitzen, was im Zusammenhang mit dem Abbau der Lipoide stehen muß*). Bei einigen Fällen der Lues cerebri wurde ausnahmslos ebenfalls eine ausgesprochene, und zwar vorzugsweise starke Erhöhung des antiproteolytischen Vermögens festgestellt; derartige Befunde widersprechen den Angaben von Stü m p ke ${ }^{36}$ ), welcher nur bei den metaluetischen Prozessen ein derartiges Verhalten annimmt und bei der Syphilis eine Herabsetzung der antitryptischen Kraft gefunden hat.

Ein wechselndes Verhalten zeigen die arteriosklerotischen Abbauerkrankungen des Gehirns. Während nach dem apoplektischen Insult und überhaupt bei den ausgedehnten Herden mit starkem Untergang des Nervengewebes das durch die Resorption der Abbaustoffe lipoidreiche Blutserum sehr hohe Werte der antitryptischen Kraft (Index X-XII) zeigte, wurde bei den diffusen, langsam progredierenden Erkrankungen eine geringere Steigerung nachgewiesen.

Der chronische Alkoholismus kann gewöhnlich eine leichte und manchmal nur deutliche Erhöhung der antiproteolytischen Hemmungskörper verursachen, auch dann, wenn er nicht zu einer organischen progressiven Erkrankung, wie z. B. die Lebercirrhose, die alkoholische Pseudoparalyse oder Korsakowsche Psychose geführt hat. Bei den letzten Erkrankungen, besonders aber bei dem akuten Intoxikations-

*) Es wurden gleichzeitig Untersuchungen über das lipolytische Vermögen bei der Paralyse, Epilepsie und Delirium tremens mit der von He nriot angegebenen Monobutyrinmethode, welche von Citron und Reicher ${ }^{10}$ ) bei der Prüfung der luetischen Sera angewandt wurde, angestellt. Da aber das Wesen dieser Reaktion vollständig unaufgeklärt ist, besonders der fermentative Charakter der Monobutyrinspaltung durch das Serum zweifelhaft erscheinen kann, so muß die ausführliche Besprechung der erhaltenen Befunde verschoben werden, bis die Untersuchungen über die biologischen Eigenschaften der Serumlipolyse abgeschlossen werden. 
zustand des Delirium tremens finden sich bedeutende Steigerungen der antitryptischen Kraft, was verständlich ist, wenn man die chemische Affinität des Alkohols zu den Gehirnlipoiden in Betracht zieht.

Tabelle V. Delirium tremens.

\begin{tabular}{|c|c|c|c|c|c|c|c|c|}
\hline \multicolumn{3}{|c|}{ Antitr. Kraft } & \multicolumn{2}{|c|}{ Vor der Krise } & \multicolumn{2}{|c|}{ Nach der Krise } & \multicolumn{2}{|c|}{ Zusammen } \\
\hline w. & Char. & Ind. & Zahl & Summa & Zahl & Summa & Zahl & $\%$ \\
\hline \multirow{2}{*}{$\mathrm{N}$} & - & VI & 0 & 0 & 1 & 1 & 1 & 5 \\
\hline & \pm & VII & 0 & 0 & 1 & 1 & 1 & 5 \\
\hline \multirow{3}{*}{$\mathrm{H}$} & + & $\begin{array}{l}\text { VIII } \\
\text { IX }\end{array}$ & $\begin{array}{l}2 \\
2\end{array}$ & 4 & $\begin{array}{l}3 \\
3\end{array}$ & 6 & 10 & 50 \\
\hline & $+t$ & $\begin{array}{r}\mathrm{X} \\
\mathrm{XI}\end{array}$ & $\begin{array}{l}2 \\
3\end{array}$ & 5 & $\begin{array}{l}2 \\
0\end{array}$ & 2 & 7 & 35 \\
\hline & +++ & XII & 1 & 1 & 0 & 0 & 1 & 5 \\
\hline
\end{tabular}

So hatten auf der Höhe des Deliriums 6 Kranke eine sehr starke Erhöhung des Hemmungsvermögens (Ind. X-XII), die übrigen vier eine deutliche Steigerung (Ind. VIII-IX). In keinem einzigen Falle des ausgebildeten Deliriums konnte ein normales Verhalten oder eine nur geringe Steigerung (Ind. VII) der antitryptischen Kraft festgestellt werden. Da aber das Delirium tremens, wie es Elzhol z ${ }^{15}$ ) nachgewiesen hat, mit einer Polynucleose, welche nach der Krise verschwindet, einhergeht, so müßte beim Zerfall der vermehrten neutrophilen Leukocyten durch die Absättigung des proteolytischen Fermentes derselben eine Verminderung der antiproteolytischen Substanzen resp. eine rasche Herabsetzung der vorher erhöhten antitryptischen Kraft stattfinden. Dementsprechend konnte ich bei 5 Alkoholdeliranten eine Abnahme des Hemmungsvermögens des Serums um zwei, bei 2 Kranken nur um 1 Grad nach dem kritischen Schlafe feststellen; die 2 Fälle, bei welchen keine sofortige Senkung nach der Krise stattgefunden hat, zeigten dann einen protrahierten Verlauf. Daß trotz der kritischen Herabsetzung meistens noch in der Rekonvaleszenz eine geringe Erhöhung der antitryptischen Kraft zurückbleibt, ist wohl auf die Folgen des chronischen Alkoholismus zurückzuführen.

\section{Die antitryptische Kraft bei der Epilepsie.}

Die Untersuchungen über das Verhalten der antiproteolytischen Hemmungskörper, welche hauptsächlich an Epileptikern, aber auch bei anderen organischen Psychosen, bei der Hysterie, sowie an normalen Personen ausgeführt wurden, haben im ganzen über 200 Befunde ergeben. Daraus wurden aber nur 80 Bestimmungen, welche von einwandfreien 32 Fällen der genuinen Epilepsie stammen, als Grundlage für diese Betrachtungen verwertet. Es wurden namentlich alle die- 
jenigen Epileptiker, bei welchen irgendeine andere Bedingung für ein abnormes Verhalten des anitproteolytischen Hemmungsvermögens des Blutserums, also einerseits physiologische Vorgänge der Gravidität, anderseits organische Abbauprozesse der Arteriosklerose, infektiöse Erkrankungen, wie die Lues und die floride Tuberkulose, und exogene Intoxikationen, besonders der Alkoholismus vorgelegen waren, bei der Zusammenstellung der Resultate von der Berücksichtigung ausgeschlossen. Da es der Hauptzweck der Untersuchung war, das Verhalten der antitryptischen Kraft in ihrer Beziehung zu den Anfällen klarzulegen und in dieser Hinsicht die Krankheitsbilder, bei welchen die Anfälle resp. die Anfallsserien periodisch auftreten und voneinander durch längere Intervalle von ungefähr bekannter Zeitdauer getrennt sind, besonders geeignet erschienen, so wurde ich veranlaßt, 40 Bestimmungen, also die Hälfte der Gesamtzahl, am Serum von 12 Epileptikerinnen, welche meistens einen menstruellen Typus im Auftreten der Anfälle zeigten, auszuführen. Da aber die innerhalb der menstruellen Phase erhobenen Befunde bedenklich erscheinen könnten, so wurden dieselben bei der statistischen Zusammenstellung auch gesondert von den übrigen 40 Bestimmungen, welche vorzugsweise von den männlichen Epileptikern und einigen jugendlichen, außerhalb der Menstruation stehenden weiblichen Fällen stammen, berechnet; außerdem wurde das Verhalten der antitryptischen Kraft während der Periode bei anderen Psychosen und bei normalen Personen zur Kontrolle herangezogen. Soweit es möglich war, wurden die Bestimmungen bei demselben Patienten wiederholt, so daß nur 8 Befunde von den Einzeluntersuchungen stammen; dagegen bei manchen Epileptikern, besonders bei den erwähnten menstruellen, konnte das Serum 4-6 mal untersucht werden. Die Blutentnahmen wurden dabei mit Rücksicht auf die Vermehrung der Hemmungssubstanzen während der Verdauung ständig vor dem Mittagsmahl, gewöhnlich immer zu derselben Zeit (11 Uhr) entnommen. Wenn z. B. der Eintritt eines Anfalls eine sofort darauf folgende Entnahme des Serums zu einer anderen Zeit veranlaßt hatte, so wurden die dabei gewonnenen Resultate nur mit aller Vorsicht verwertet.

Das Gesamtergebnis der Bestimmungen nach der Zusammenrechnung aller Befunde ohne Rücksicht auf die Beziehung jedes einzelnen zu den Anfällen lautet, daß 53,75\% der Blutsera bezüglich des Gehaltes an antiproteolytischen Hemmungskörpern hohe Indexwerte (HW) ergeben haben, obwohl die geringe Erhöhung der antitryptischen Kraft (Ind. VII), welche in 30\% nachgewiesen wurde, der Vorsicht wegen mit den $16,25 \%$ Befunden, welche normales Verhalten gezeigt hatten, zu der Kategorie der niederen Werte (NW), die demnach $46,25 \%$ der Gesamtzahl beträgt, zusammengestellt wurde. Wenn 
Tabelle VI. Zusammenstellung aller Befunde bei der Epilepsie.

\begin{tabular}{|c|c|c|c|c|c|c|c|}
\hline \multirow{2}{*}{ Char. } & \multirow{2}{*}{ Ind. } & \multicolumn{2}{|c|}{ Menstruelle Fälle } & \multicolumn{2}{|c|}{ Gewöhnliche Fälle } & \multicolumn{2}{|c|}{ Zusammen } \\
\hline & & Zahl & $\%$ & Zahl & $\%$ & Zahl & $\%$ \\
\hline- & $\begin{array}{c}\text { V } \\
\text { VI }\end{array}$ & $\begin{array}{ll}4 \\
7\end{array} 11$ & 27,5 & $\begin{array}{ll}12 \\
\end{array}$ & 5 & $\begin{array}{ll}5 & 13 \\
8\end{array}$ & 16,25 \\
\hline \pm & VII & 1212 & 30 & 1212 & 30 & 2424 & 30 \\
\hline+ & $\begin{array}{l}\text { VIII } \\
\text { IX }\end{array}$ & $\begin{array}{l}9 \\
6\end{array}$ & 37,5 & $\begin{array}{l}11 \\
11\end{array} 22$ & 55 & $\begin{array}{l}20 \\
17\end{array}$ & 46,25 \\
\hline++ & $\begin{array}{c}\mathrm{X} \\
\mathrm{XI}\end{array}$ & $\begin{array}{ll}2 & 2 \\
0 & 2\end{array}$ & 5 & $\begin{array}{ll}3 & 4 \\
1 & 4\end{array}$ & 10 & $\begin{array}{ll}5 & 6 \\
1 & \end{array}$ & 7,5 \\
\hline \multicolumn{2}{|c|}{$\mathrm{N} \mathrm{W}$} & 23 & 57,5 & 14 & 35 & 37 & 46,25 \\
\hline \multicolumn{2}{|c|}{$\mathrm{H} \mathrm{W}$} & 17 & 42,5 & 26 & 65 & 43 & 53,75 \\
\hline
\end{tabular}

man die menstruellen und gewöhnlichen Fälle gesondert betrachtet, so stellt sich heraus, daß bei der ersten Gruppe eine viel größere Anzahl der Sera, nämlich $27,5 \%$, einen normalen Gehalt antiproteolytischer Substanzen hat, während in den anderen das nur bei $5 \%$ festgestellt wurde. Die Häufigkeit der geringen Steigerung (Ind. VII) ist gleich und beträgt $30 \%$; dagegen eine deutliche Steigerung ist im Gegensatz zu der ersten Differenz nur um 37,5\% der menstruellen Fälle, während sie bei den gewöhnlichen $\mathbf{5 5} \%$ beträgt; ebenso verhält sich die starke Steigerung mit 5\% in der ersten und $10 \%$ in der zweiten Gruppe. Diese Unterschiede bedingen es, daß die menstruelle Epilepsie relativ kleinere Zahl der hohen Werte, nämlich $42,5 \%$, den $65 \%$ der nicht menstruierenden Fälle gegenüber gezeigt hat. Derartige Resultate lassen sich wohl dadurch erklären, daß bei den letzteren die Untersuchungen hauptsächlich während der Anfallsserien resp. im Status epilepticus ausgeführt werden konnten; dagegen bei den menstruellen ebenso viele Blutentnahmen auch nach der Periode resp. den Anfallen und in der interparoxysmalen Zeit gemacht wurden.

Das Verhalten der antiproteolytischen Hemmungskörper in eine Beziehung zu dem epileptischen Anfall zu setzen, ist durch die wechselnde Häufigkeit der Insulte äußerst schwierig; die Intervalle können hier nicht, wie z. B. bei der Periode, als eine ungefähr konstante Größe betrachtet werden, weil sie von verschiedener Dauer sind. Deshalb mußte bei der Klassifizierung der Befunde ein Einteilungsprinzip der zwischen zwei Anfällen vorhandenen Pause durchgeführt werden. Die erste Stunde nach dem Insult wurde als das paroxysmale Stadium zu der direkten Anfallswirkung, namentlich der gesteigerten Muskeltätigkeit und der Krampfasphyxie, zugerechnet und die während desselben erhobenen Befunde sind gesondert registriert und bei der Berechnung aus später zu erörternden Gründen nicht in Betracht 
gezogen worden. Die danach folgenden $2 / 5$ der Intervallzeit wurden als die postparoxysmale Phase gedeutet, das mittlere $1 / 5$ als die interparoxysmale im engeren Sinne und die letzten $2 / 5$ sollen schon als das präparoxysmale Stadium betrachtet werden. Es gibt einerseits Fälle, bei welchen zwischen den präparoxysmalen und postparoxysmalen Befunden keine Differenzen bestehen; aber die meisten Fälle hatten einen wechselnden Antitrypsingehalt, und die Bestimmungen von den letzteren wurden einer Zusammenstellung unterzogen.

Tabelle VII. Beziehung zum epileptischen Anfall.

\begin{tabular}{|c|c|c|c|c|c|c|c|c|c|c|c|}
\hline \multicolumn{3}{|c|}{ Antitr. Kraft } & \multicolumn{3}{|c|}{ Vor d. Anfall } & \multicolumn{3}{|c|}{ Nach d. Anfall } & \multicolumn{3}{|c|}{ Zusammen } \\
\hline w. & Char. & Ind. & Zahl & Sa. & $\%$ & Zahl & Sa. & $\%$ & Zahl & $\%$ & Res. \\
\hline \multirow[t]{2}{*}{$\mathrm{N}$} & - & $\begin{array}{c}\text { V } \\
\text { VI }\end{array}$ & $\begin{array}{l}0 \\
0\end{array}$ & 0 & \multirow{2}{*}{$\begin{aligned} & 2 \\
= & 20 \%\end{aligned}$} & $\begin{array}{l}2 \\
4\end{array}$ & 6 & \multirow{2}{*}{$\begin{array}{c}9 \\
=90 \%\end{array}$} & 6 & 30 & \multirow{2}{*}{$\begin{aligned} & 11 \\
= & 55 \%\end{aligned}$} \\
\hline & \pm & VII & 2 & 2 & & 3 & 3 & & 5 & 25 & \\
\hline \multirow[t]{2}{*}{$\mathrm{H}$} & + & $\begin{array}{c}\text { VIII } \\
\text { XI }\end{array}$ & $\begin{array}{l}5 \\
2\end{array}$ & 7 & \multirow{2}{*}{$\begin{array}{c}8 \\
=80 \%\end{array}$} & $\begin{array}{l}1 \\
0\end{array}$ & 1 & \multirow{2}{*}{$\begin{array}{c}1 \\
=10 \%\end{array}$} & 8 & 40 & \multirow{2}{*}{$\begin{array}{c}9 \\
=45 \%\end{array}$} \\
\hline & $+t$ & $X$ & 1 & 1 & & 0 & 0 & & 1 & 5 & \\
\hline
\end{tabular}

Während von 10 Epileptikerseris aus der präparoxysmalen Zeit acht einen hohen Indexwert, nämlich eine deutliche Steigerung, und zwei einen niedrigen Gehalt der antitryptischen Substanzen, aber trotzdem beide eine geringe Erhöhung zeigten, fanden sich bei der gleichen Zahl der postparoxysmalen Befunde neun mit niederen Werten, davon sogar sechs mit einem vollkommen normalen antitryptischen Vermögen. Nur in einem Falle wurde die geringste Stufe der hohen Werte, nämlich Ind. VIII festgestellt (dabei ist es möglich, daß hier die Anfallsserie nicht abgeschlossen war, denn die Patientin mußte nach der letzten Blutentnahme in die Anstalt transferiert werden).

Die gegenseitige Beziehung der Befunde in der Anfallszeit, sowie das Verhalten der antitryptischen Kraft direkt innerhalb des paroxysmalen Stadiums wird zuerst an einigen Beispielen erörtert, wobei die Periode nicht in Betracht kommt.

\section{Beobachtung A.}

Thomas W., 12 Jahre, ist hereditär nicht belastet; hat an Fraisen nicht gelitten, 1905 ein schweres Schädeltrauma, indem er vom Tramwaywagen geschleudert wurde und mit dem Kopf auf das Straßenpflaster gefallen ist; dabei Bewußtlosigkeit, Nasenbluten und Zungenbiß. Der erste klassische epileptische Anfall 1907; nach einer Exstirpation der Tonsillen zehnmonatliche Pause, dann aber gehäuftes Auftreten der Insulte. 1909 Behandlung in der Klinik, wonach dieselben 1 mal monatlich aufzutreten pflegten. Nachdem der Pat. zuletzt sich im Anfalle die linke Kopfhälfte verletzt hat, ist ein Status epilepticus entstanden. Bei den Anfällen Bewußtlosigkeit, Zungenbiß und Sezessus; die Augen werden nach rechts 
verdreht, starke tonische und klonische Krämpfe, besonders rechts. Motorische Kraft rechts weniger wie links; Mundfacialis ebenfalls. Die Sehnenreflexe gesteigert, besonders rechts Babinski und Fußklonus rechts. Die Intelligenz ohne nachweisbare Störung.

\section{Beobachtung B.}

Albine A., 27 Jahre, keine Heredität, hat an Fraisen nicht gelitten. Der erste Anfall im 9. Lebensjahre, die nächsten in fünf- bis neunmonatlichen Intervallen. Nachdem sich im 15. Lebensjahre die Periode eingestellt hat, kommen die Anfälle meistens zur Zeit derselben. Die Pat. hat zwei Schwangerschaften durchgemacht, wobei die Anfälle gehäuft waren; Geburt normal, während der Laktation wenig Anfälle. Die Krämpfe sind tonisch und klonisch, dabei Bewußtlosigkeit und Zungenbiß; die Dämmerzustände treten postparoxysmal oder als selbständige Äquivalente auf und dauern einige Stunden. Die Pat. ist weinerlich und etwas zornig, wenn ihre Wünsche nicht erfüllt werden. Das Gedächtnis relativ gut erhalten; dagegen die Merkfähigkeit und das Urteilsvermögen herabgesetzt. Somatische Untersuchung o. B.

\section{Beobachtung C.}

Marie B., 20 Jahre, hat Fraisen im 8. Lebensjahre gehabt, während der Schuljahre anfallsweise Herzklopfen, Schwindelgefühl und Angstlichkeit. Der erste Krampfanfall mit Bewußtlosigkeit, Zungenbiß, tonischen und klonischen Krämpfen im 14. Lebensjahre. Die Insulte kommen jetzt gewöhnlich serienweise (4-5 mal) nach der Periode, selten vor derselben, nicht aber während der Blutung. Nach den Anfällen öfters Benommenheit und ängstliche Halluzinationen, welche sogar einige Tage andauern. Die Pat. ist leicht deprimiert und weinerlich, die Intelligenz ohne Defekt. Somatischer Befund: Die Reflexe der Extremitäten lebhaft, eine Andeutung von Fußklonus.

\section{Beobachtung D.}

Auguste Tr., 28 Jahre, litt in der Kindheit an Fraisen; seit dem 10. Lebensjahre Anfälle mit Bewußlosigkeit, tonischen und klonischen Krämpfen, Zungenbiß und Sezessus. Die Häufigkeit ist wechselnd: manchmal pausieren die Anfälle einige Tage, dann treten sie gehäuft auf; nach den Insulten ist die Patientin einige Stunden verwirrt und neigt dabei zu Gewalttaten, sie zerschlägt alles und will auf die Angehörigen losgehen; die Demenz kam vor 11/2 Jahren zum Vorschein, jetzt ist sie hochgradig.

Somatischer Befund: Die Skleral- und Gaumenreflexe fehlen; die Zunge weicht beim Ausstrecken nach rechts ab, das Gaumensegel wird links höher gehoben, die Sprache verwaschen. Patellarsehnenreflexe lebhaft; nach dem Anfall vorübergehend Babinski, die Wassermannsche Reaktion negativ.

\section{Beobachtung E.}

Leopoldine S., 27 Jahre, hat Fraisen im 1. und 2. Lebensjahre gehabt, die typischen epileptischen Anfälle treten seit dem 7. Lebensjahre mit wechselnder Häufigkeit auf, manchmal nach Intervallen von 8 Tagen, ein anderes Mal 2-3 mal am Tage, zuletzt gehäuft; sie werden durch ein Kältegefühl im Rücken und ein „Zusammenziehen“ in der Herzgegend eingeleitet, die Krämpfe sind vorwiegend tonisch, die Klonismen sind selten und wenig ausgesprochen. Nach den Anfällen etwas benommen, hat Kopfschmerzen; die Merkfähigkeit und Gedächtnis sind stark herabgesetzt. 
Somatischer Befund: Patellarsehnenreflexe lebhaft links mehr wie rechts, kein Babinski, Dilatatio cordis nach rechts, Herztöne rein. An der rechten Lungenspitze eine Schallverkürzung. Wassermann negativ.

Wenn man die hohen Werte (Tabelle $\alpha$ ) der antitryptischen Kraft während einer Anfallsserie resp. im Status epilepticus (Fall A) mit dem niederen Ind. VII, welcher nach dem Aufhören der Anfälle zu erheben war, vergleicht, so gewinnt man den Eindruck, daß die postparoxysmale

Beob. A.

\section{Tabelle $\alpha$.}

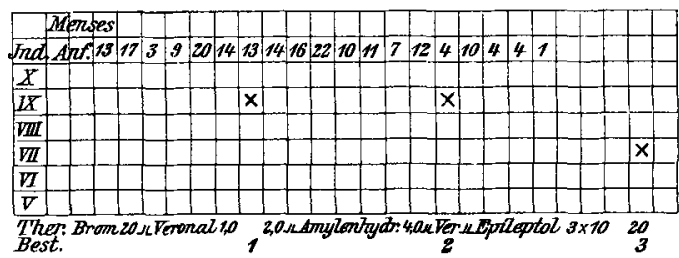

Beob. B.

Beob. C.

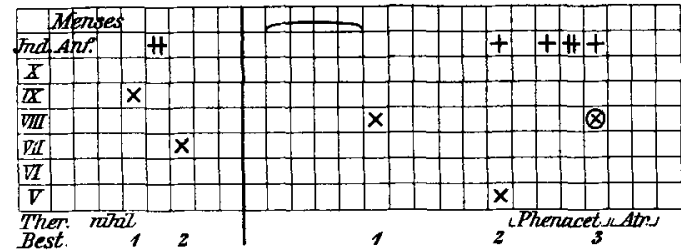

Beob. D.

Beob. E.

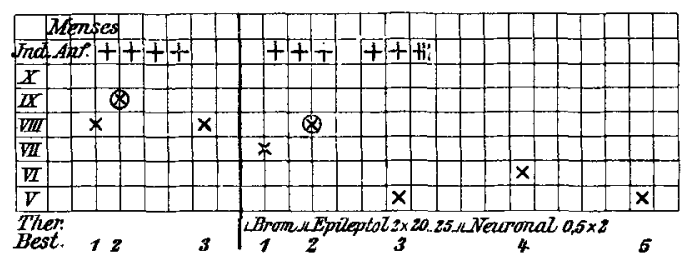

$\otimes$ Befunde innerhalb der paroxysmalen Phase.
Phase sich durch eine Verminderung der antiproteolytischen Substanzen kennzeichnet (was aus dem Falle D ersichtlich ist). $\mathrm{DaB}$ dieses Verhalten mit dem Anfall in Zusammenhang steht, beweist die Beobachtung $\mathrm{B}$, wo sich das präparoxysmale Stadium durch eine deutlicheSteigerung der antitryptischen Kraft auszeichnete, während nach den zwei am nächsten Tage erfolgten Anfällen das Serum am 3. Tage einen normalen Gehalt an antitryptischen Körpern hatte. Dasselbe zeigen die Bestimmungen 1 und 2 im Falle C. Dagegen hat die Blutentnahme 3 , welche innerhalb der paroxysmalen Phase direkt nach

dem letzten (Atropinwirkung?) konvulsiven Insult einer Anfallsserie ausgeführt wurde, ein Resultat ergeben, welches anfangs paradox erschien und in anscheinendem Widerspruch mit den Ergebnissen der anderen, meistens erst in einigen Stunden nach dem Anfall erfolgten Serumentnahmen sich befand. Nachdem aber im Falle D, bei welchem die erste Blutentnahme 1/2 Stunde dem Anfall vorausging, die zweite innerhalb $1 / 4$ Stunde nach dem Aufhören der Krämpfe gemacht wurde und dabei trotz der präparoxysmalen deutlichen Steigerung der antitryptischen Kraft noch eine Erhöhung um einen Indexgrad beim gleichzeitigen 
Titrieren der beiden Sera sich nachweisen ließ, so mußte man mit Rücksicht auf die früher geschilderten Tatsachen annehmen, daß die Krämpfe infolge einer Muskelanstrengung eine vorübergehende Vermehrung der antitryptischen Substanzen hervorrufen, was durch andere Befunde, z. B. im Falle E, bestätigt wurde. Diese Erscheinung ist anscheinend besonders bei den mit starken klonischen Krämpfen einhergehenden Anfällen, wie es die beiden angeführten waren, nachweisbar, und ist bezüglich der Dauer von der Intensität derselben abhängig. Nach den weniger ausgeprägten Konvulsionen äußert sich diese Wirkung manchmal nur dadurch, daß die postparoxysmale Senkung der antitryptischen Kraft nicht sofort nach dem Anfalle eintreten kann, sondern die vor demselben vorhandene Vermehrung der antitryptischen Substanzen noch kurze Zeit andauert. Es ist möglich, daß bei den leichten Anfällen mit tonischem Charakter die postparoxysmale Herabsetzung der antitryptischen Kraft bald nach dem Insulte zustandekommt; das Verhalten im paroxysmalen Stadium ist demnach von der Eigenart des Krampfanfalles abhängig und deshalb auch äußerst wechselnd.

Was die Beziehung zwischen der Periode und dem Gehalt des Blutserums an den antiproteolytischen Hemmungskörpern anbetrifft, so konnte diese Frage zuerst an 4 Epileptikerinnen, bei welchen infolge der Behandlung oder 'zufällig die Krampfanfälle während der menstruellen Phase entweder vollständig ausgeblieben sind (Fall G) oder durch ein Äquivalent, wie die Migräne (Fall I), die prämenstruelle Verwirrtheit (Beob. H) oder sogar ein Zornaffekt (Pat. F) vertreten wurden.

\section{Beobachtung $\mathbf{F}$.}

Alice C., 37 Jahre, hat Fraisen in der Kindheit beim Keuchhusten, dann Pneumonie und 1890 Typhus durchgemacht; Wasserman $n$ sche Reaktion negativ. Die Periode ist im 13. Lebensjahre eingetreten, seit dem 16. Lebensjahre klassische epileptische Anfälle, welche ungefähr alle 8-10 Tage, vor: der Periode gewöhnlich gehäuft auftreten. Einige Zeit vor dem Insult bekommt die Pat. ein Gefühl der Abwesenheit, manchmal neigt sie dabei zu Beeinträchtigungsvorstellungen und wird sogar infolgedessen aggressiv. Die Merkfähigkeit ist mangelhaft, das Gedächtnis für die Schulkenntnisse abgeschwächt.

Somatische Untersuchung ergibt eine abgelaufene alte Spitzenaffektion, am Nervensystem und Herzen nichts.

\section{Beobachtung G.}

Barbara H., 31 Jahre, erkrankte im 6. Monate nach der Geburt an einer „Gehirnentzündung“ mit einer darauffolgenden Lähmung der linken Körperhälfte. Im 1. und 3. Lebensjahre wieder Krampfanfälle (Fraisen?), Trunksucht wird bestritten, Wassermann negativ. Die Periode ist unregelmäßig, die Krampfanfälle treten jetzt mit einer sehr wechselnden Häufigkeit auf: manchmal Pausen von einigen Monaten, der letzte direkt vor der Einlieferung in die Klinik. Dämmerzustände sollen nicht vorkommen. Die Pat. ist verstimmt, unzufrieden, zornig, die Intelligenz intakt. 
Somatischer Befund: Jie motorische Kraft der Extremitäten links schwächer wie rechts. Patellarsehnenreflex links lebhafter wie rechts, Babinski links + , rechts - , die Bauchdeckenreflexe links - , rechts + , die linke Zungenhälfte ist atrophisch.

\section{Beobachtung $H$.}

Marie S., 37 Jahre, leidet an typischen epileptischen Anfällen seit 4 Jahren, dieselben kommen jede 2-4 Wochen, besonders gehäuft vor der Periode; die Krämpfe sollen hauptsächlich einen tonischen Charakter haben, vor den Anfällen klagt die Pat. über „Magenkrämpfe“; nach dem Insult wird sie öfters verwirrt, neigt zu Gewalttaten und zum Suicid, was manchmal auch ohne den vorausgegangenen Anfall geschieht. Am 25. Juli ist die Pat. im Zustande einer derartigen Benommenheit vom 1. Stock heruntergesprungen; sie wurde bewußtlos, bekam eine Blutung aus dem Ohr und aus der Nase, hat aber nicht erbrochen.

Somatischer Befund am 26. Juli: Die Zunge weicht etwas nach links, der Mundwinkel wird rechts mehr verzogen, die Patellarsehnenreflexe nicht gesteigert, systolisches Geräusch an der Herzspitze.

\section{Beobachtung I.}

Anna Z., 28 Jahre, der Großvater der Pat. starb in einer Irrenanstalt, der Vater kein Potator, leidet aber an einer nervösen Schlaflosigkeit. Die Pat. hat keine Fraisen gehabt; die Periode seit 12. Lebensjahre sehr unregelmäßig und schmerzhaft, die klassischen epileptischen Anfälle sind zuerst im 15. Lebensjahre aufgetreten, kommen $1-2$ mal monatlich, besonders zur Zeit der Periode, sie werden gewöhnlich von Herzklopfen und Angstgefühl eingeleitet, die letzten Erscheinungen bestehen manchmal vor der Periode, ohne daß ein Insult kommt; nach den Anfällen ist die Pat. etwas benommen, sieht nur die Umrisse der Person, Stimmung ist sehr labil, Neigung zur Depression; pathetisch, bigott; ein Intelligenzdefekt besteht nicht.

Somatischer Befund: Patellarsehnenreflexe lebhaft, links mehr wie rechts, die Pupillen eng, die Lichtreaktion etwas mängelhaft.

\section{Tabelle $\beta$.}

Beob. F.

Beob. G.

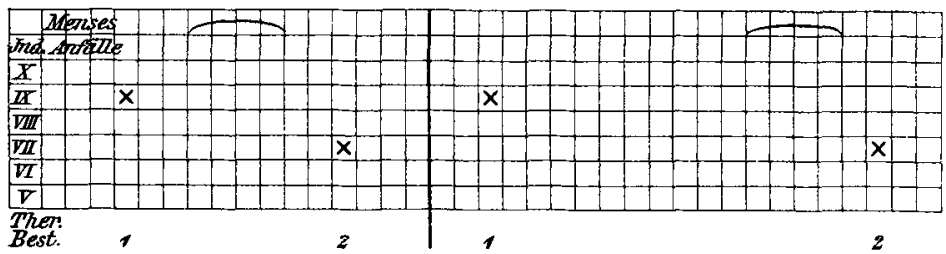

Beob. H.

Beob. I.

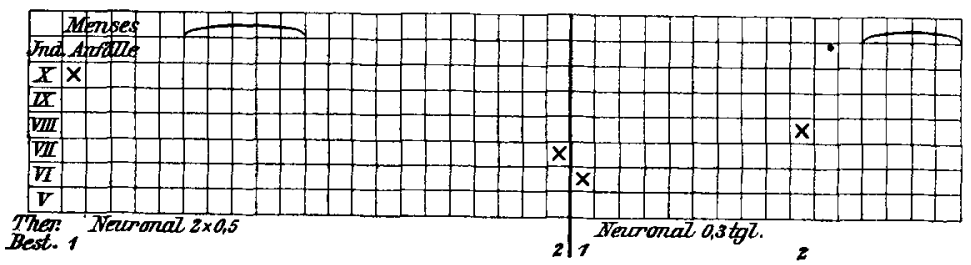


Es hat sich, wie die Tabelle $\beta$ zeigt, herausgestellt, daß in allen angeführten Fällen das antiproteolytische Hemmungsvermögen des Blutserums vor der Periode hohe Werte, nämlich Indexgrade von VIII bis $\mathrm{X}$ hatte und nach dem Aufhören der menstruellen Blutung zu niederen Werten um 2 Grade herabgesunken war. Die Untersuchung 10-12 Tage nach der Periode (Fall H) läßt annehmen, daß in der intermenstruellen Zeit die antitryptische Kraft nur eine geringe Erhöhung zeigt und dann erst bei der Näherung der menstruellen Phase (Beob. I) wieder anzusteigen pflegt; es wurde zwar bei der Pat. G. schon 11 Tage vor dem Eintritt der Menses eine deutliche Steigerung des antitryptischen Vermögens festgestellt, aber die Periode war in diesem Falle verspätet, so daß die Zeit der ersten Blutentnahme zu der prämenstruellen Phase gerechnet werden kann. Man mußte infolge derartiger Befunde Kontrolluntersuchungen anstellen, und dieselben haben ergeben, daß bei den normalen weiblichen Personen vor der Periode gewöhnlich eine geringe Erhöhung der antitryptischen Kraft, welche gewöhnlich den Indexgrad VII und nur selten VIII erreicht; nach den Menses war das Hemmungsvermögen meistens sehr niedrig (V-VI Grade). Dieses Verhalten ist aber wahrscheinlich nicht konstant, denn bei einer Versuchsperson wurden normale Werte vor der Periode festgestellt, bei einer anderen Frau ließ sich keine postmenstruelle Senkung nachweisen; dagegen bei einer Pat., wo anscheinend eine Katatonie vorlag, fand sich ein ähnliches Verhalten wie bei der Epilepsie.

Nachdem das Verhalten der antiproteolytischen Substanzen bei dem epileptischen Anfall und bei der Periode gesondert betrachtet wurde, müssen jetzt die Schwankungen des Hemmungsvermögens bei den verschiedenen Konstellationen, welche durch das gleichzeitige oder nacheinander folgende Vorkommen dieser beiden Momente entstehen können, an der Hand der entsprechenden Beobachtungen geschildert werden.

\section{Beobachtung K.}

Mathilde B., 27 Jahre, leidet seit ihrem 12. Lebensjahre an ausgesprochenen konvulsiven epileptischen Anfällen, welche in Intervallen von 15 Tagen bis zwei Monaten, zuletzt gewöhnlich zur Zeit der Periode, welche im 17. Jahre sich eingestellt hat, aufzutreten pflegen. Nach dem Insult häufig Schwindelgefühl. Die Pat. ist öfters verstimmt, aber fleißig und ruhig.

Somatischer Befund: Nystagmus beim Blick nach rechts, leichte Schwerhörigkeit links, die Herztöne dumpf, ein leichtes Struma, Puls 84.

\section{Beobachtung $\mathbf{I}$.}

Marie W., 23 Jahre, der Vater der Pat. ist an Gehirnhautentzündung mit Aufregungszuständen gestorben; die Pat. hatte, als sie $1 \frac{1}{2}$ Jahre alt war, Fraisen, seit dem 12. Lebensjahre leidet sie an Krampfanfällen, welche meistens zur Zeit der Periode gehäuft aufzutreten pflegen, mit Bewußtlosigkeit und Zungenbiß 
einhergehen; danach wird die Pat. öfters desorientiert, sie halluziniert, spricht verwirrt, neigt zu Gewalttaten, einmal wollte sie sogar ihre Tante umbringen. Pat. ist zornig und aufregbar, aber arbeitsam und fromm, das Gedächtnis ist leicht abgeschwächt, dagegen das Urteilsvermögen stark herabgesetzt.

Somatischer Befund: Geringe Dilatatio cordis nach links; an der Spitze und an der Basis leichtes systolisches Geräusch; Wassermann negativ.

\section{Beobachtung M.}

Rosa W., 37 Jahre, hat an Fraisen nicht gelitten; Potus gering, aber an scheinend besteht eine Alkoholintoleranz. Die Pat. bekam den ersten Krampf. anfall im 29. Lebensjahre einige Wochen nach der Geburt des dritten Kindes. während der damals vorzeitig eingetretenen Periode. Anfangs kamen die Anfälle wöchentlich, dann unter der Brombehandlung hat sich ein menstrueller Typus eingestellt; während der zwei folgenden Schwangerschaften gehäuftes Auftreten der Anfälle; zuletzt während der menstruellen Phasen kamen dieselben 2-3 mal täglich, die Anfälle sind vorzugsweise tonisch, nur wenige klonische Zuckungen. Nach der Anfallsserie langdauernde Verwirrtheitszustände mit zornigem Affekt und Wahnbildung; die Pat. ist verstimmt, neigt zu Streitigkeiten, hochgradige Gedächtnisschwäche.

So matischer Bef u nd: Lebhafte Papillarsehnenreflexe, abgelaufene Spitzenaffektion, Wassermann negativ.

\section{Beobachtung N.}

Else Sch., 24 Jahre, hat keine Fraisen, dagegen im 8. Lebensjahre Scharlach durchgemacht, die Periode ist im 13. Lebensjahre aufgetreten und war regelmäßig; Juni 1909 plötzlich ein typischer epileptischer Anfall mit starken tonischen und klonischen Krämpfen; die Anfälle haben sich während der ersten 5 Monate jede 6 Tage wiederholt, dann wurden sie unter der Brombehandlung seltener, zuletzt 1-2 mal monatlich. Aura wird nicht angegeben. Dämmerzustände sind nicht vorgekommen. Die Pat. ist etwas reizbar und weinerlich.

Somatischer Befund: Einige klonische Nachzuckungen bei Achillessehnenreflexen, die Zunge weicht etwas nach rechts, der Gaumen links mehr wie rechts gehoben, Babinski negativ.

\section{Beobachtung 0 .}

Anna S., 19 Jahre, litt im 1. Lebensjahre an Fraisen, Periode im 15. Jahre eingetreten, 1 Jahr später der erste epileptische Anfall mit Zungenbiß, die Insulte treten jetzt mit wechselnder Häufigkeit, gewöhnlich menstruell auf; manchmal Pausen bis $1 / 2 \mathrm{Jahr}$, dann aber gehäuft wieder jede 5 Tage, aber dafür leichter Charakter der Anfälle ohne Klonismen; manchmal klagt die Pat. während der menstruellen Phase nur über Schwindelgefühl und Kopfweh; Merkfähigkeit ist etwas herabgesetzt. Das Urteilsvermögen gut erhalten.

Somatischer Befund: Palpable Schilddrüse, Adipositas; die Skleralreflexe herabgesetzt, Würgreflexe fehlen, Wassermann negativ.

Bei der Betrachtung (Tabelle $\gamma$ ) der Verminderung des Hemmungsvermögens im Falle $\mathbf{K}$, wo die zweite Blutentnahme prämenstruell und zugleich präparoxysmal, die dritte nach einem postmenstruellen Anfall erfolgte, kann man nicht beurteilen, welches Moment bei der Schwankung gewirkt hat; eine Erklärung dafür gibt aber der Fall L. Wenn die An- 
fälle, wie es besonders häufig geschieht, erst einige Tage nach dem Aufhören der menstruellen Blutung auftreten und daher das postmenstruelle Stadium mit dem präparoxysmalen zusammenfälltt, so muß es vorkommen, daß die postmenstruelle Senkung in diesem Falle nur einen Grad beträgt und das Serum noch den Indexwert VIII, bis der nächstfolgende Anfall den Antitrypsingehalt auf den niedrigen Grad VII bringt;

\section{Tabelle $\gamma$.}

Beob. K.

Beob. L.

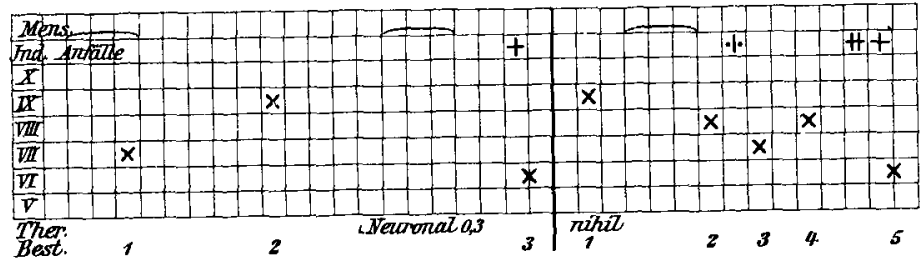

Beob. M.

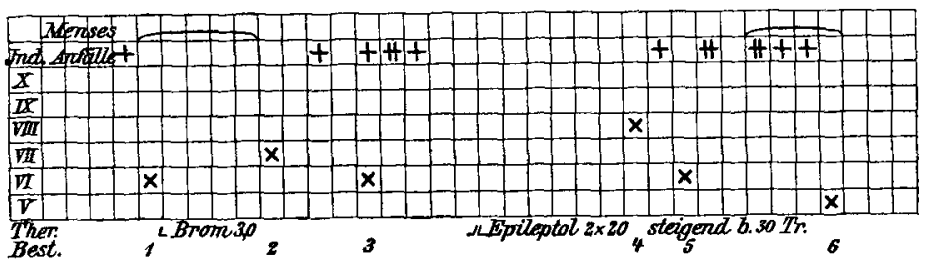

Beob. N.

Beob. O.

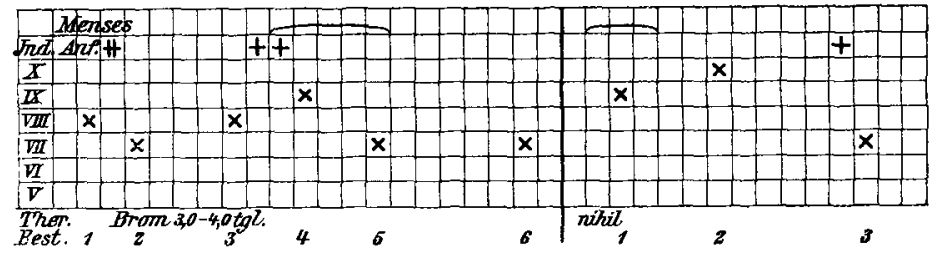

deshalb hat von 10 Bestimmungen aus der postmenstruellen Zeit eine, namentlich die obige, einen hohen Wert der antitryptischen Kraft ergeben, während die übrigen 9 Sera die niederigen Indexgrade VI-VII hatten. Wenn die Anfälle vor der Periode auftreten (Beob. M.), so besteht eine Koinzidenz des prämenstruellen mit dem postparoxysmalen Stadium, wodurch die prämenstruellen Werte der antitryptischen Kraft (Best. 5) herabgesetzt werden; manchmal kann nach dieser postparoxysmalen Senkung noch vor der Periode eine Vermehrung der antiproteolytischen Substanzen stattfinden, wofür die Bestimmungen 1-3 im Fall N. sprechen. Es muß übrigens betont werden, daß, während 
bei der letzten Beobachtung auch die Befunde 5 und 6 mit anderen Ergebnissen übereinstimmen, das Resultat der Untersuchung 4, welches auf eine Steigerung der antitryptischen Kraft während der postparoxysmalen Phase am 2. Tage der menstruellen Blutung hindeutet, vollkommen unverständlich erscheint; obwohl der vorausgegangene Anfall mit starken Klonismen einhergegangen ist, so ist wegen der zeitlichen Momente unmöglich, hier eine Krampfwirkung anzunehmen. Man muß noch erwähnen, da $\beta$ die Bestimmungen $1-3$ in der Beobachtung $M$. eine ,,paradoxe" Schwankung der antitryptischen Kraft in der Beziehung zu der Periode zeigen; dieses Verhalten wird dadurch bedingt, daß außer dem prämenstruellen Anfall auch einige postmenstruelle aufgetreten sind und dementsprechend das vor der Periode durch den ersten herabgesetzte Hemmungsvermögen nach den Menses in der präparoxysmalen Phase der zweiten Anfallsgruppe erhöht wurde. Die geschilderten Tatsachen machen es verständlich, daß 8 Sera aus der prämenstruellen Phase (Tabelle VIII) einen hohen Gehalt an antitryptischen Substanzen zeigten und zwei Befunde eine niedere Hemmungskraft ergeben hatten, was man auf die Koinzidenz mit dem postparoxysmalen Zustand zurückführen kann.

Tabelle VIII. Beziehung zu der Periode bei den Epileptikerinnen.

\begin{tabular}{|c|c|c|c|c|c|c|c|c|c|c|c|}
\hline \multicolumn{3}{|c|}{ Antitr. Kraft } & \multicolumn{3}{|c|}{ Vor der Periode } & \multicolumn{3}{|c|}{ Nach der Periode } & \multicolumn{3}{|c|}{ Zusammen } \\
\hline w. & Char. & Ind. & Zahl & Sa. & $\%$ & Zahl & Sa. & $\%$ & Zahl & $\%$ & Res. \\
\hline \multirow[t]{2}{*}{$\mathrm{N}$} & & $\begin{array}{l}\text { V } \\
\text { VI }\end{array}$ & $\begin{array}{l}0 \\
1\end{array}$ & 1 & \multirow{2}{*}{$\begin{aligned} & 2 \\
= & 20 \%\end{aligned}$} & $\begin{array}{l}1 \\
3\end{array}$ & 4 & \multirow{2}{*}{$\begin{array}{c}9 \\
=90 \%\end{array}$} & 5 & 25 & \multirow{2}{*}{$\begin{aligned} & 11 \\
= & 55 \%\end{aligned}$} \\
\hline & & VII & 1 & 1 & & 5 & 5 & & 6 & 30 & \\
\hline \multirow[t]{2}{*}{$\mathrm{H}$} & & $\begin{array}{l}\text { VIII } \\
\text { IX }\end{array}$ & $\begin{array}{l}3 \\
4\end{array}$ & 7 & \multirow{2}{*}{$\begin{aligned} & 8 \\
= & 80 \%\end{aligned}$} & $\begin{array}{l}1 \\
0\end{array}$ & 1 & \multirow{2}{*}{$\begin{array}{c}1 \\
=10 \%\end{array}$} & 8 & 40 & \multirow{2}{*}{$\begin{aligned} & 9 \\
= & 45 \%\end{aligned}$} \\
\hline & & $\mathrm{X}$ & 1 & 1 & & 0 & 0 & & 1 & 5 & \\
\hline
\end{tabular}

Diese Resultate bezüglich der Schwankung der antitryptischen Kraft während der Periode entsprechen im allgemeinen dem Verhalten, welches für die Beziehung des Hemmungsvermögens zu den epileptischen Anfällen festgestellt wurde. Während aber von 9 niederen Werten der postparoxysmalen Befunde 6 mit normalem Gehalt an antitryptischen Substanzen und nur 3 eine geringe Steigerung derselben zeigten, finden sich bei derselben Zahl der postmenstruellen nur 4 epileptische Sera mit normalem Verhalten, was wahrscheinlich durch eine Äußerung der zugleich bestehenden präparoxysmalen Steigerungen zu erklären ist. Deshalb darf man annehmen, daß die Schwankungen der antitryptischen Kraft bei der menstruellen Epilepsie durchaus nicht ausschließlich von der Periode abhängig sind, sondern im Zusammenhang mit dem Auftreten der Anfälle sich befinden. 
Die Ergebnisse der Untersuchungen zusammenfassend, kann man sagen, daß

1. nach der Berechnung aller Befunde bei der Epilepsie ohne Rücksicht auf die Beziehung jedes einzelnenzu den Anfällen, ungefähr bei der Hälfte der epileptischen Sera ein erhöhter Gehalt der antiproteolytischen Substanzen besteht;

2. das präparoxysmale Stadium sich meistens durch eine deutliche Vermehrung der antitryptischen Kraft kennzeichnet und nach dem Anfall sich niedere Werte des Hemmungsvermögens finden;

3. während der interparoxysmalen Phase gewöhnlich nur eine geringe Erhöhung der antitryptischen Kraft, in manchen Fällen sogar ein vollkommen normales Verhalten derselben besteht;

4. eine bedeutende Steigerung des antiproteolytischen Hemmungsvermögens bei den Epileptikern vor der Periode, wenn auch die Anfälle während derselben nicht eintreten, beobachtet werden kann;

5. die prämenstruelle Erhöhungderantitry ptischen Kraft im geringeren Grade auch bei den normalen weiblichen Personen besteht;

6. der Krampfanfall eine vorübergehende Vermehrung der antiproteolytischen Substanzen, welche von der Intensität der gesteigerten Muskeltätigkeit abhängig, demnach äußerst wechselnd ist und rasch verschwindet, hervorruft.

\section{Die Beziehung des Hemmungsvermögens des Blutserums zur Pathologie der Epilepsie.}

Was die Deutung der erhobenen Befunde anbetrifft, so könnte von allen Veränderungen der antitryptischen Kraft, welche bei der Epilepsie vorkommen, eigentlich nur das Verhalten in der paroxysmalen Phase, obwohl dasselbe äußerst wechselnd ist, am leichtesten erklärt werden. Wenn man nämlich einerseits die früher geschilderte Wechselbeziehung zwischen der gesteigerten Muskeltätigkeit der ,,myogenen“" Leukocytose vnd der dabei bestehenden Steigerung des Hemmungsvermögens des Blutserums, andererseits aber das von Kr u mb miller ${ }^{25}$ ) nachgewiesene und von Rohde bestätigte Auftreten einer vorübergehenden Leukocytose, welche auch bezüglich ihres morphologischen Bildes mit der myogenen Leucocytose von Grawitz ${ }^{17}$ ) übereinstimmt, bei den epileptischen Anfällen in Betracht zieht, so wird man geneigt sein, die paroxysmalen Erhöhungen des Hemmungsvermögens auf eine Anhäufung der entsprechenden Stoffwechselprodukte im Blute zurück- 
zuführen. Wenn dieses Verhalten trotzdem bei verschiedenen Anfällen inkonstant ist, so befindet sich das in Übereinstimmung mit der Angabe von Tintemann ${ }^{37}$ ), wonach der Grad der Leukocytose von der Intensität und der Dauer der Konvulsion abhängig ist. Die beiden Erscheinungen können wohl von der Menge der bei den Krämpfen entstehenden Dissimilationsprodukte der Muskelsubstanz abhängig sein. Da die infolge einer 5 Minuten dauernden Muskelanstrengung auftretende Leukocytose schon nach 30 Minuten verschwinden soll und Krumbmiller ${ }^{25}$ ) in einer Stunde nach dem epileptischen Anfall das normale Blutbild gefunden hat, so wäre es zu erwarten, daß nach dem Zugrundegehen der Leukocyten durch die Absättigung des proteolytischen Fermentes derselben gleichzeitig die Erhöhung des Hemmungsvermögens abnehmen soll. Es konnte aber trotz der vielen Blutentnahmen eine übereinstimmende Dauer für die paroxysmale Steigerung der antitryptischen Kraft nicht festgestellt werden.

Bei der Beurteilung des Ergebnisses, daß das präparoxysmale Stadium sich durch eine Vermehrung der antiproteolytischen Substanzen kennzeichnet und nach dem Anfall sich niedrige Werte der antitryptischen Kraft gewöhnlich finden, entsteht die Frage, ob wirklich eine präparoxysmale Steigerung der antitryptischen Kraft vorliegt oder vielleicht sich die epileptische Erkrankung durch einen ständigen erhöhten Gehalt an antitryptischen Substanzen, welcher durch die Absättigung des aus der paroxysmalen Leukocytose stammenden proteolytischen Fermentes nur vorübergehend vermindert wird, auszeichnet. Gegen eine derartige Auffassung spricht vor allem das Eintreten einer postparoxysmalen Senkung ganz unabhängig von der Intensität der Krämpfe, also auch in denjenigen Fällen, wo der Insult sich durch einen tonischen Charakter auszeichnete (Beob. E., M., O.), außerdem die Befunde während des Intervalles, welche zeigen, daß die antitryptische Kraft längere Zeit nach dem Anfall auf einer relativ niedrigen Stufe bleibt, (Beob. E., J., N.), und erst mit dem Nähern der Anfallszeit anzusteigen pflegt. Bei der genuinen Epilepsie, wenn man von den präparoxysmalen Erhöhungen vorläufig absieht, kann also das untere Niveau der antitryptischen Kraft, bis zu welchem das Hemmungsvermögen nach den Anfällen sinkt, in manchen Fällen sogar vollkommen normale Werte aufweisen (Beob. E., J., M.); in anderen findet man meistens eine geringe Vermehrung der antitryptischen Substanzen, resp. den Ind. VII. Die letzte Erscheinung könnte man einerseits dadurch erklären, daß, wie Alzheimer ${ }^{2 a}$ ) nachgewiesen hat, bei der genuinen Epilepsie sogar von den Anfällen gewissermaßen unabhängig ein chronischer Abbauprozeß der Rindensubstanz, welcher sich in einer Degeneration der nervösen Elemente und einer hauptsächlich als die Randgliose imponierenden Wucherung der Neuroglia äußert, besteht; man 
muß anderseits auch berücksichtigen, daß in manchen ebenfalls lipoidhaltigen Drüsenorganen der inneren Sekretion bei der Epilepsie, wie es Claude und Schmiergeld ${ }^{11}$ ) angegeben haben, teilweise sklerotische Vorgänge, aber auch gesteigerte Funktionen sich abspielen. Es wäre anzunehmen, daß lipoide Abbauprodukte in das Blutserum übergehen und auf die Proteolyse eine hemmende Wirkung ausüben, welche, der Intensität der epileptischen Rindengeneration entsprechend, bedeutend schwächer wie bei der Paralyse sein muß.

Wenn also die statistische Zusammenstellung aller Bestimmungen der antitryptischen Kraft bei der Epilepsie ergibt, daß ungefähr in der Hälfte der Befunde eine bedeutende Vermehrung der Hemmungssubstanzen besteht, so darf man noch nicht annehmen, daß, wie es z. B. die 15 einmaligen nach der Jakobschen Methode berechneten Bestimmungen von $\mathrm{Jach}^{19}$ ) schließen lassen könnten, die Epilepsie als solche sich durch eine Vermehrung der antitryptischen Substanzen auszeichnet, denn die meisten hohen Werte sind durch die präparoxysmalen Steigerungen bedingt.

Das Zustandekommen einer präparoxysmalen Erhöhung der antitryptischen Kraft möchte man ebenfalls durch eine vermehrte Anhäufung der lipoiden Abbauprodukte des Nervengewebes erklären und somit das für die Epilepsie eigentümliche Verhalten des antiproteolytischen Hemmungsvermögens auf eine einheitliche Ursache zurückführen können. Dịe histopathologischen Forschungen Alzheimers²) haben ergeben, daß bei der Epilepsie neben der erwähnten chronischen Rindenerkrankung, durch welche die geringen Erhöhungen der antitryptischen Kraft in der Intervallzeit bedingt zu sein scheinen, auch akute Abbauvorgänge am Nervengewebe, welche mit Anfällen im Zusammenhang stehen, stattfinden. Neuerdings betont Alzh ei m e ${ }^{2 b}$ ), daß diese regressiven Vorgänge an nervösen Elementen dem Auftreten des epileptischen Anfalls vorausgehen, so daß der letztere erst nach einer gewissen Ausbildung der histologischen Veränderungen zustande kommt. Es wäre deshalb möglich, daß dieser akute Zerfallsprozeß in der Rinde die Ursache der präparoxysmalen Anhäufung der antiproteolytischen Gehirnlipoide im Blute sein könnte. Dagegen läßt es sich einwenden, daß die lipolytische Kraft des Blutserums, welche in einer Beziehung zu den Abbauvorgängen der Lipoidsubstanzen stehen sollte, nämlich beim gesteigerten Zerfall derselben nach Wassermann ${ }^{38}$ ) bedeutend erhöht sein müßte, bei der genuinen Epilepsie, wie auf Grund von 20 eigenen Bestimmungen ausgesagt werden kann, nicht erhöht ist, oder nur eine geringe Steigerung zeigt; dies steht im Gegensatz zu den Ergebnissen von Citron und Reicher ${ }^{10}$ ), welche vorwiegend luetische Epileptiker verwertet haben. Weiter habe ich keine Schwankungen der lipolytischen Kraft in der Beziehung zu den Anfällen feststellen können; 
es wurden bei der Pat. B. (Best. 1-2), L. (Best. 2-3) und N. (Best. 1-2) dieselben Befunde für das lipolytische Vermögen erhoben, während der Gehalt an den antiproteolytischen Substanzen nach dem Anfall eine typische Verminderung erlitten hat; bei der Pat. D. zeigte sich im Anfallsstadium einerseits eine paroxysmale Erhöhung der antitryptischen Kraft, anderseits eine Verminderung des lipolytischen Vermögens. Die Methodik und das biologische Wesen der lipolytischen Eigenschaften des Blutserums ist aber trotz der vielen Arbeiten von Hénriot und Achalme vorläufig zu wenig aufgeklärt, um auf Grund derartigen Verhaltens für unsere Frage entscheidende Schlüsse ziehen zu dürfen.

Vielleicht könnten dagegen für die Lipoidnatur der vermehrten antiproteolytischen Substanzen die autohämolytischen Eigenschaften des epileptischen Blutserums sprechen. Diese Erscheinung ist von Citron und Reicher ${ }^{19}$ ) beobachtet worden und wurde als eine Folge des Bromismus aufgefaßt. Dadurch wurde ich veranlaßt, die Farbe der Sera nach dem Abzentrifugieren des Blutgerinnsels protokollieren, wobei es sich herausgestellt hat, daß zwischen 75 epileptischen Seris 36 die normale Farbe hatten $(48 \%)$, 15 leicht rot waren $(20 \%)$ und 24 $(=36 \%)$ eine deutliche rote Färbung zeigten. Dieses Verhalten wurde aber ebenso einerseits bei den Epileptikern, welche mit Bromsalzen nicht behandelt wurden (Beob. C., H.), anderseits manchmal auch bei den Paralytikern und besonders häufig bei dem Delirium tremens beobachtet. Es ist also möglich, daß die Bromsalze bei der Epilepsie die autohämolytischen Vorgänge begünstigen, indem sie einen hypertonischen Zustand der Körpersäfte erzeugen und dadurch die Resistenz der Erythrocyten herabsetzen; die hämolytische Wirkung kann aber auch mit der Vermehrung der Serumlipoide in Zusammenhang gebracht werden. Obwohl die autohämolytischen Sera bei der Epilepsie meistens aus der Anfallszeit stammen, konnte irgendwelche charakteristische Beziehung zum Insult nicht festgestellt werden; in manchen Fällen (L. und M.) war das Serum autohämolytisch nach dem Anfall, dagegen bei der Pat. E. im präparoxysmalen Stadium, bei vielen Epileptikern war die Farbe des Serums in beiden Phasen vollkommen normal.

Wenn man einen vor dem Anfall gesteigerten Abbau der lipoidhaltigen Hirnsubstanz als die Ursache der präparoxysmalen Erhöhung der antitryptischen Kraft angenommen hat, so wäre ein derartiger Vorgang mit der Ansicht von Binswanger ${ }^{6}$ ), daß eine Anhäufung der abnormen Substanzen im Blute vor dem epileptischen Anfall eine Folge des pathologischen Zustands der Nervenzentra ist, zu vergleichen. Man muß aber betonen, daß durch die Annahme eines cerebralen Ursprungs der präparoxysmalen Erhöhung der antiproteolytischen Substanzen die Möglichkeit eines Zusammenhangs der Schwankungen der 
antitryptischen Kraft mit der epileptischen Stoff wechselstörung gelockert wurde; denn es wäre unverständlich, warum die an das Blutserum im gesteigerten Maße abgegebenen Hirnlipoide gerade bei der Epilepsie den intermediären Eiweißabbau beeinträchtigen sollten, während z. B. bei der Paralyse, wo die Abbauvorgänge im Gehirn viel bedeutender sind und dementsprechend die antiproteolytischen Substanzen des Blutserums ständig beträchtlich vermehrt sind, eine derartige Wirkung nicht entfaltet wird.

Bei der Berücksichtigung der Analogie, welche bei der Epilepsie zwischen dem Verhalten der antiproteolytischen Substanzen und der von Rohde ${ }^{33}$ ) nachgewiesenen Stoffwechselstörung besteht, könnte man das vor dem Anfall erhöhte Hemmungsvermögen des epileptischen Blutserums der Proteolyse gegenüber als einen Ausdruck des herabgesetzten Vermögens des epileptischen Organismus den Eiweißabbau zu bewerkstelligen, betrachten. Wenn man einerseits die leichte Retention des Stickstoffs mit der'geringen Vermehrung der antitryptischen Kraft in der interparoxysmalen Zeit, anderseits die hochgradige Verzögerung des Eiweißabbaues vor dem Anfall mit der präparoxysmalen Steigerung des Hemmungsvermögens und endlich die vermehrte Ausscheidung des Stickstoffes mit der Verminderung der antiproteolytischen Substanzen nach dem Anfall zusammenstellt, so wäre es verlockend die Stoffwechselstörung bei der Epilepsie auf abnorme Zustände der Selbstregulation der proteolytischen Organfermente, resp. auf die Störungen der inneren Sekretion zurückzuführen. Die wichtigen Befunde von Claude und Schmiergeld ${ }^{\mathbf{1 1}}$ ), daß die Thyreoidea bei den meisten Fällen der genuinen Epilepsie ein der Hypofunktion entsprechendes Bild darzubieten pflegt, könnten für diese Deutung verwertet werden, ebenso das von Raimann ${ }^{31}$ ) bei den Epileptikern festgestellte Bestehen einer hohen Assimilationsgrenze für die Kohlenhydrate, was auch für eine Hypofunktion des acceleratorischen Drüsensystems spricht.

Die Organe der inneren Sekretion stehen vielfach in einer antagonistischen Beziehung zueinander, so daß dem geschilderten Verhalten der befördernden Blutdrüsen vielleicht auch eine Hyperfunktion der retardatorischen Gruppe entsprechen dürfte. Man könnte nämlich an eine gesteigerte Tätigkeit der Nebenniere, welche, wie es neuerdings Bied $1^{9}$ ) betont hat, als die Bildungsstätte der Blutlipoide betrachtet werden könnte, denken; es müßte angenommen werden, daß die aus der inneren Sekretion stammenden Blutlipoide im Gegensatz zu den lipoiden Zerfallsprodukten, z. B. des Gehirns, nicht nur im Blute kreisen und das antiproteolytische Vermögen des Serums erhöhen, sondern auch eine korrelative Wirkung ausüben und die Bildung der proteolytischen Organfermente beeinträchtigen können. 
Demnach wurde das Verhalten der antitryptischen Kraft des Blutserums von zwei verschiedenen Momenten beeinflußt, nämlich einerseits von der Menge des proteolytischen Ferments, welches vor den epileptischen Anfällen resp. der Periode, vielleicht bei einer gleichzeitigen Vermehrung der lipoiden Produkte der inneren Sekretion, vermindert sein dürfte, so daß dadurch die intermediäre Proteolyse hemmend beeinflußt wird, anderseits von den myogenen antiproteolytischen Stoffwechselprodukten, welche erst beim Anfall durch die krampfartige Muskelanstrengung vermehrt werden und ohne auf den Eiweißabbau einen hemmenden Einfluß auszuüben, nur die vorübergehende paroxysmale Erhöhung verursachen könnten.

Die Annahme eines ,echten“ Antitrypsins, welches nach Berg$\operatorname{mann}{ }^{5}$ ) und $\mathrm{Meyer}^{26}$ ) in Pankreas gebildet wird, wäre eine weitgehende und gefährliche Hypothese, weil einerseits nach Cla ude und Schmiergeld ${ }^{11}$ ) diese Drüse bei der Epilepsie meistens vollkommen normal bleibt und anderseits damit eine spezifische Substanz, deren Existenz einwandfrei nicht nachgewiesen ist, angenommen werden müßte.

Man muß aber auch noch die Möglichkeit erwägen, ob vielleicht die Schwankungen im Gehalt des Blutserums an antiproteolytischen Substanzen nicht als die Ursache der epileptischen Stoffwechselstörung, sondern als die Folgezustände derselben a ufgefaßt werden sollen. Wenn beim gesteigerten Eiweißstoffwechsel, welcher z. B. beim Morbus Basedowii besteht, eine Überschwemmung des Blutserums mit den antiproteolytischen Eiweißlipoidverbindungen stattfindet, so könnte bei einer Verzögerung des Stickstoffabbaues eine Anhäufung der abnormen Produkte der intermediären Stoffwechselstörung eintreten. Damit im Einklang dürfte die Angabe von Rohde ${ }^{33}$ ) gebracht werden, da $\beta$ vor dem Anfall die ätherlöslichen organischen Produkte vermehrt werden; nach Allers ${ }^{1}$ ) kommen auch die stickstoffhaltigen intermediären Substanzen in Betracht; endlich wird nach dem Anfall die Fleischmilchsäure in beträchtlichen Mengen ausgeschieden. Da aber aus der Neutralisation der organischen Säuren eine vermehrte Bildung der Ammoniakverbindungen, welche nach Donath ${ }^{13}$ ) eine krampferregende Wirkung ausüben sollen, resultiert, so müßte die Frage aufgeworfen werden, ob die präparoxysmale Vermehrung der antiproteolytischen Substanzen durch eine Ansammlung der Zwischenprodukte des verzögerten Eiweißabbaues resp. der Ammoniaksalze der ätherlöslichen organischen Säuren bedingt und demnach als ein Ausdruck einer Anhäufung der toxischen Substanzen angesehen werden könnte. Deshalb ist die Wirkung der Milchsäure und ihrer Salze, besonders des milchsauren Ammoniums, welches sich nach intravenösen Injektionen bei Kaninchen als ein starkes Krampfgift erwiesen hat, auf die tryptische Verdauung 
des Caseins untersucht worden, indem für jede zu prüfende Substanz eine aufsteigende Reihe, welche $1,0-2,0-\ldots-10,0$ einer 1 proz. Trypsinlösung enthielt, neben einer ähnlichen den Trypsintiter bestimmenden Kontrolle aufgestellt wurde. Die Milchsäure wurde als $0,1 \mathrm{ccm}$ einer 0,01 proz. Lösung, was $0,00001 \mathrm{ccm}$ entspricht, angewandt, nachdem es nachgewiesen wurde, daß diese Menge in der entsprechenden Konzentration weder eine lösende noch koagulierende Wirkung auf $2 \mathrm{ccm}$ einer $1 \%$ Caseinlösung allein auszü̈ben imstande ist; von dem milchsauren Ammonium wurden bedeutend größere Mengen, nämlich $0,1 \mathrm{ccm}$ einer 10 proz. Lösung $(=0,001)$ genommen. Es hat sich herausgestellt, daß weder die reine Milchsäure noch das milchsaure Ammonium einen hemmenden Einfluß auf die Trypsinproteolyse ausüben.

Deshalb ist man wohl berechtigt anzunehmen, daß die aus der epileptischen intermediären Stoffwechselstörung stammenden ätherlöslichen organischen Säuren nicht als die Ursache der gleichzeitig bestehenden Vermehrung der antiproteolytischen Substanzen betrachtet werden können.

Wenn man die präparoxysmale Steigerung der antitryptischen Kraft mit dem verzögerten Eiweißabbau in Zusammenhang bringen möchte, wofür eine ähnliche Koinzidenz bei manchen physiologischen Vorgängen, nämlich in der prämenstruellen Zeit spricht, wie es aus Untersuchungen von Schrader ${ }^{\mathbf{3 4}}$ ) hervorzugehen scheint, so dürfte man eher das er höhte Hemmungsvermögen des Blutserums der fermentativen Proteolyse gegenüber als den Ausdruckeiner Hypofunktion der den intermediären Eiweißstoff wechsel a uf dem Wege der inneren Sekretion befördernden Momente ansehen. Deshalb darf man auch nicht die präparoxysmale Erhöhung des Hemmungsvermögens mit einer Anhäufung der toxischen Substanzen, welche krampfauslösend wirken sollten, in einen direkten Zusammenhang bringen, denn die letzteren scheinen das fermentative Blutbild nicht beeinflussen zu können.

Die Beziehung des antiproteolytischen Vermögens des Blutserums bei der Epilepsie zu der inneren Sekretion soll aber nicht in dem Sinne gedeutet werden, daß die Entstehung der epileptischen Anfälle durch eine Störung der chemischen Korrelation erklärt sein könnte oder daß bei allen Krankheitsbildern der Epilepsie ein direkter pathogenetischer Zusammenhang mit dem Funktionszustand des acceleratorischen Drüsensystems resp. der Thyreoidea und der Ovarien, wie es Paris ${ }^{29}$ ) behauptet hat, angenommen werden dürfte. Denn das Wesen der Epilepsie liegt, wie es neuerdings Redlich ${ }^{32}$ ) definiert hat in einer abnormen Reaktionsweise des Gehirns auf verschiedene mechanische Reize und chemische Schädlichkeiten, welche exogenen Ursprungs 
sind oder im Organismus gebildet werden, aber alle auf das Gehirn in gleicher Weise schädigend wirken und eine epileptische Entladung verursachen können. Nachdem aber das Gehirn auf diese Schädlichkeiten mit einer epileptischen Reaktion geantwortet hat, so wird die Empfindlichkeit dieses vorgebildeten epileptischen Mechanismus dadurch gesteigert, so daß die Nervenzentra auf viele, unter anderen Umständen unterschwelligen Reize mit einem Krampfanfall reagieren werden. Bei den genuinen Formen der Epilepsie kann die erhöhte epileptische Reizbarkeit des Gehirns angeboren sein. Wenn aber z. B. ein labiles kindliches Gehirn bei einer parathyreogenen Intoxikation einer Spasmophilie unterlag, so ist verständlich, daß dasselbe danach für verschiedene Reize, welche sonst keine krampferregende Wirkung auszuüben brauchen, darunter aber besonders für die abnormen Stoffwechselprodukte überempfindlich wird. Deshalb entstehen die epileptischen Insulte, unter denjenigen Umständen, bei welchen auch im normalen Organismus eine Tendenz zur Verzögerung des Stoffwechsels innerhalb der physiologischen Grenze besteht, z. B. zur Zeit der Periode, welche nach Untersuchungen von Schrader ${ }^{34}$ ) sich durch eine prämenstruelle Stickstoffretention und wie unsere Bestimmungen erwiesen haben, durch ein entsprechendes Verhalten des antiproteolytischen Hemmungsvermögens auszeichnet. Dieses beiderseitige Verhalten müßte durch die prämenstruellen antagonistischen Zustände in den Ovarien, welche einerseits das Auftreten der Periode regulieren, andererseits einen acceleratorischen Einfluß auf den Stoffwechsel ausüben sollen, erklärt werden.

Zum Schluß der Arbeit erlaube ich mir Herrn Professor Wagner v. Jauregg für die Úberlassung des Krankenmaterials und für das entgegengebrachte Interesse und Herrn Professor Biedl für die liebenswürdige Leitung der Untersuchungen und die vielfache Förderung derselben, meinen verbindlichsten Dank auszusprechen.

\section{Literaturverzeichnis.}

1. Allers, Tatsachen und Probleme der Stoffwechselpathologie in ihrer Bedeutung für die Psychiatrie. Journ. f. Psychol. u. Neurol. 16. 1910.

2. Alzheimer, a) Die anatomische Gruppierung der Epilepsie. Allgem. Zeitschr. f. Psych. 64. 1907. b) Beziehungen der path. Neuroglia zu den Abbauvorgängen im Nervengewebe. Histol. Arbeiten v. Nißl 3, H. 3, 1910.

3. Bauer, Die antiproteolytisch wirkende Substanz im Harn und Serum. Dio Zeitschr, f. Immunitätsforschung 5, H. 2-3, 1910.

4. Becker, Antitrypsingehalt des Blutes in der Gynäkologie. Münch. med. Wochenschr. 1907, Nr. 27. 
5. Bergmann u. Meyer, Klinische Bedeutung der Antitrypsinbestimmung im Blute. Berl. klin. Wochenschr. 1909, Nr. 37.

6. Binswanger, Epilepsie. Wien 1899.

7. Bornstein, A., Die chemische Zusammensetzung des Blutes bei der Paralyse. Monatsschr. f. Psych. 25. 1909.

8. Brieger u. Trebing, Die antitryptische Kraft des menschlichen Blutserums. Berl. klin. Wochenschr. 1908.

9. Biedl, Innere Sekretion. Wien 1910.

10. Citron u. Reicher, Das Fettspaltungsvermögen syphilitischer Sera. Berl. klin. Wochenschr. 1908, Nr. 30.

11. Cla ude et Sch miergeld, Les glandes à sécretion interne chez les épileptiques. Encéphale 1909.

12. Doeblin, Untersuchungen über die Natur des Antitrypsins. Zeitschr. f. Immunitätsforschung 4, H. 1-2. 1909.

13. Donath, Die bei der Auslösung der epileptischen Anfälle beteiligten Substanzen. Deutsche Zeitschr. f. Nervenheilk. 32. 1907.

14. Eis ner, Die antifermentative Wirkung des Blutserums. Zeitschr. f. Immunitätsforschung I, H. 5. 1909.

15. Elzholz, Beitrag zur Kenntnis des Delirium tremens. Jahrb. f. Psych. 15. 1897.

16. Glaeßner, Antitryptische Wirkung des Blutes. Hofmeisters Beiträge zur chemischen Physiologie 10, 1904.

17. Grawitz, Ernst, Die myogene Leukocytose. Deutsche med. Wochenschr. 1910, Nr. 29.

18. Haig, The formation and excretion of uric acid. Brain 1891.

19. Jach, Antitrypsingehalt des Blutserums bei Geisteskranken. Münch. med. Wochenschr. 1909, Nr. 44.

20. Jakob, Beitrag zur Frage der klinischen Bedeutung der Antitrypsinbestimmung im Blute. Münch, med. Wochenschr. 1909, Nr. 27.

21. Jochmann u. Kantorowicz, Antitrypsine und Antipepsine im menschlichen Blutserum. Zeitschr. f. klin. Medizin 66. 1908.

22. I no ye u. Saiki, Auftreten der abnormen Bestandteile im Harn nach epileptischen Anfällen. Zeitschr. f. physiol. Chemie 3\%. 1903.

23. Ka u fma n n, Die Pathologie des Stoff wechsels bei Psychosen 2. Die Epilepsie. 1908.

24. Krainsky, N., Zur Pathologie der Epilepsie. Allgem. Zeitschr. f. Psych. 54. 1898.

25. Krumbmiller, Arch. des sciences biol. de St. Petersbourg 1908. Zit. n. Rohde.

26. Meyer, Kurt, Die antiproteolytische Wirkung des Blutserums und ihre Beziehung zum Eiweißstoffwechsel. Berl. klin. Wochenschr. 1909, Nr. 23.

27. Müller u. Jochmann, Zur Kenntnis des proteolytischen Fermentes und seines Antifermentes. Verhandlg. d. Kongr. f. Inn. Med. Wiesbaden 1907.

28. Peritz, Georg, Das Verhältnis von Lues, Tabes und Paralyse zum Lecithin. Zeitschr. f. experim. Pathol. u. Ther. 5, 1909.

29. Paris, Epilepsie, pathogénie et indications thérapeutiques. Arch. de Neurologie 1\%. 1904.

30. Pick u. Przibram, Beiträge zur Kenntnis der ätherempfindlichen und ätherlöslichen Substanzen des Blutserums und ihr Einfluß auf einige Immunitätsreaktionen. Biochem. Zeitschr. 11. 1908.

31. Raiman n, Glykosurie bei Geisteskranken. Zeitschr. f. Heilkunde 33. 1902. 
624 S. Rosental: Das Verhalten der antiproteolytischen Substanzen usw.

32. Redlich, Die Beziehungen zwischen der genuinen und symptomatischen Epilepsie. Deutsche Zeitschr. f. Nervenheilk. 36. 1909.

33. Rohde, Stoff wechselversuche an Epileptikern. Deutsches Archiv f. klin. Medizin 95. 1909.

34. Schrader, Stoff wechsel während der Menstruation. Zeitschr. f. klin. Medizin 25. 1894.

35. Schwarz, Die Natur des Antitrypsins im Serum und der Mechanismus seiner Wirkung. Wiener klin. Wochenschr. 1909, Nr. 33.

36. Stümpke, Die antitryptischen Stoffe bei Syphilis. Med. Klin. 1910, Nr. 6.

37. Tintemann, Zur Stoff wechselpathologie der Epilepsie. Münch. med. Wochenschr. 1909, Nr. 29.

38. Wassermann, Berl. klin. Wochenschr. 1910, Nr. 26. Diskussion in der Berl. med. Gesellsch. zum Vortrag Freudenberg. 